OPEN ACCESS

Edited by:

Vance L. Trudeau,

University of Ottawa, Canada

Reviewed by:

Andrea Tamas,

University of Pécs, Hungary

Hitoshi Hashimoto,

Osaka University, Japan

*Correspondence:

David Vaudry

david.vaudry@univ-rouen.fr

Asma Cherait

a.cherait@yahoo.com

Specialty section:

This article was submitted to

Neuroendocrine Science,

a section of the journal

Frontiers in Endocrinology

Received: 19 July 2020 Accepted: 22 October 2020 Published: 20 January 2021

Citation:

Cherait A, Maucotel J, Lefranc B, Leprince J and Vaudry D (2021) Intranasal Administration of PACAP

Is an Efficient Delivery Route

to Reduce Infarct Volume and

Promote Functional Recovery After

Transient and Permanent Middle

Cerebral Artery Occlusion.

Front. Endocrinol. 11:585082. doi: 10.3389/fendo.2020.585082

\section{Intranasal Administration of PACAP Is an Efficient Delivery Route to Reduce Infarct Volume and Promote Functional Recovery After Transient and Permanent Middle Cerebral Artery Occlusion}

\author{
Asma Cherait $^{1,2,3^{*}}$, Julie Maucotel ${ }^{1,4}$, Benjamin Lefranc ${ }^{1,4}$, Jérôme Leprince ${ }^{1,4}$ \\ and David Vaudry ${ }^{1,4 *}$
}

1 Normandie Univ, UNIROUEN, Inserm U1239, Laboratory of Neuronal and Neuroendocrine Communication and Differentiation, Neuropeptides, Neuronal Death and Cell Plasticity Team, Rouen, France, ${ }^{2}$ Department of Natural and Life Sciences, Faculty of Sciences, University of Algiers, Algiers, Algeria, ${ }^{3}$ Laboratory of Valorization and Bioengineering of Natural Resources, University of Algiers, Algiers, Algeria, ${ }^{4}$ Normandie Univ, UNIROUEN, Regional Cell Imaging Platform of Normandy (PRIMACEN), Rouen, France

Intranasal (IN) administration appears to be a suitable route for clinical use as it allows direct delivery of bioactive molecules to the central nervous system, reducing systemic exposure and sides effects. Nevertheless, only some molecules can be transported to the brain from the nasal cavity. This led us to compare the efficiency of an IN, intravenous (IV), and intraperitoneal (IP) administration of pituitary adenylate cyclase-activating polypeptide (PACAP) after transient or permanent middle cerebral artery occlusion (MCAO) in C57BL 6 mice. The results show that the neuroprotective effect of PACAP is much more efficient after IN administration than IV injection while IP injection had no effect. IN administration of PACAP reduced the infarct volume when injected within $6 \mathrm{~h}$ after the reperfusion and improved functional recovery up to at least 1 week after the ischemia.

Keywords: pituitary adenylate cyclase-activating polypeptide, intranasal administration, cerebral ischemia, infarct volume, functional recovery

\section{INTRODUCTION}

Stroke can either be hemorrhagic, when a cerebral blood vessel bursts, or ischemic, when an artery gets obstructed by a clot (1). In $85 \%$ of the cases, stroke is of ischemic origin due to a permanent or temporary occlusion of a cerebral artery, which in one third of the patients concerns the middle cerebral artery (MCA) (2). Stroke induced blood flow disruption, impairs oxygen and nutrients supply, inducing irreversible neuronal loss responsible for cognitive disorders, fatigue, paralysis, and even death of the patient. Actually, stroke is the second leading cause of death worldwide and the 
third leading cause of disability in adults (3). Stroke affects almost 17 million people worldwide each year, i.e., one victim every $2 \mathrm{~s}$ (4). As a consequence, millions of stroke survivors must adapt to a life with restrictions in daily activities and depend on other's continuous support (5).

A prolonged and severe reduction of cerebral blood flow (CBF) causes neuronal necrosis responsible for irreversible neurological deficits. In contrast, a moderate and gradual decline in CBF at a distance from the occlusion induces a benign oligemia which can be tolerated and remains asymptomatic. In between the core where necrosis occurs and the peripheral benign oligemia, the ischemic penumbra is a territory where neurons are on the verge of death but are still salvageable by rapid blood flow restoration and/or proper pharmacological treatment (6).

The approved medical treatments for acute ischemic stroke are intravenous (IV) thrombolysis with recombinant tissue plasminogen activator (tPA) and/or mechanical thrombectomy, which promote the recanalization of the occluded artery and therefore the rapid restoration of a normal CBF. However, tPA can only be administered within the first $4.5 \mathrm{~h}$ after the manifestation of the symptoms since after this short therapeutic time window tPA administration becomes deleterious (7). Mechanical thrombectomy can be carried out in people with large vessel ischemic stroke within the first $6 \mathrm{~h}$ after the occlusion but needs competent practitioners for this act and access to an appropriate diagnostic imaging unit (8). Application of these very limited therapeutical options is also restricted by cost, time and age of patients, so that less than $15 \%$ of stroke victims benefit from thrombolysis. Furthermore, functional recovery after thrombolysis is only partial but so far, all other therapeutic approaches targeting

\footnotetext{
Abbreviations: ACVR1, Activin A receptor 1; AQP4, Aquaporin 4; ATF3, Activating transcription factor 3; BBB, Blood brain barrier; BCL10, B cell lymphoma/leukemia 10; BDNF, Brain derived neurotrophic factor; CASP9, Caspase 9; CAT, Catalase; CBF, Cerebral blood flow; CXCR1, Chemokine receptor type 1; CXCR4, Chemokine receptor type 4; DBI, Diazepam binding inhibitor; DDIT3, DNA damage inducible transcript 3; DUSP6, Dual specificity phosphatase 6; FAS, Fas cell surface death receptor; GAD1, Glutamate decarboxylase 1; GADD45A, Growth arrest and DNA damage inducible alpha; GFAP, Glial fibrillary acidic protein; GJB6, Gap junction beta 6; GJD2, Gap Junction Protein Delta 2; GPX1, Glutathione peroxidase 1; HMOX1, Heme oxygenase 1; HOMER1, Homer scaffold protein 1; HSPA1B, Heat shock protein A (Hsp70) 1B; HSPB1, Heat shock protein beta 1; HSPD1, Heat shock protein D (Hsp60) 1; IFNAR1, Interferon alpha and beta receptor subunit 1; IL12A, Interleukin-12 subunit alpha; IL6, Interleukin-6; IN, Intranasal Injection; IP, Intraperitoneal injection; IRF1, Interferon regulatory factor 1; IRF5A, Interferon regulatory factor $5 \mathrm{a}$; IV, Intravenous injection; JUN, Jun proto-oncogene; MCAO, Middle cerebral artery occlusion; NEUROD1, Neurogenic differentiation 1; NOS1, Nitric oxide synthase 1; PAC1, Pituitary adenylate cyclase-activating polypeptide type I receptor; PACAP, Pituitary adenylate cyclase-activating polypeptide; PIK3R1, Phosphatidylinositol 3-kinase regulatory subunit alpha; pMCAO, permanent middle cerebral artery occlusion; SLC16A7, Solute Carrier Family 16 Member 7 (Monocarboxylate Transporter 2) TGFB1, Transforming growth factor-beta 2; TGFB2, Transforming growth factor-beta 2; TGFBR1, Transforming growth factor-beta receptor type 1; TIMP1, TIMP metallopeptidase inhibitor 1; TLR4, Toll-like receptor 4; tMCAO, Transient middle cerebral artery occlusion; tPA, Tissue plasminogen activator; VCAM1, Vascular cell adhesion molecule 1; VEGFA, Vascular endothelial growth factor A; VIP, Vasoactive intestinal polypeptide; VPAC1, Vasoactive intestinal polypeptide receptor 1; VPAC2, Vasoactive intestinal polypeptide receptor 1.
}

the acute phase of stroke have failed $(9,10)$. Thus, there is an urgent need for additional, more widely applicable, treatment options.

Pituitary adenylate cyclase-activating polypeptide (PACAP) is a neuropeptide of the VIP/secretin/glucagon/growth hormone-releasing hormone family, naturally produced by the organism and widely distributed in the brain and peripheral tissues, notably in the endocrine pancreas, gonads, respiratory and urogenital tracts (11). PACAP acts as a neurohormone, neurotrophic factor and neuroprotective agent, through three receptors, i.e., PAC1, VPAC1, and VPAC2 (12). PACAP has high affinity for the PAC1, VPAC1, and VPAC2 receptors, whereas VIP has $\sim 1,000$ times greater affinity for VPAC receptors than for the PAC1. The 3 receptors are largely distributed in peripheral organs (13), but PAC1 is more expressed than VPAC1 and VPAC2 in the central nervous system (14). In relationship with their large distribution, activation of those three G-protein coupled receptors initiates multiple signaling pathways involved in the regulation of important biological functions such as stress response, cardiovascular effects, food intake, circadian rythm, and reproduction $(15,16)$.

Besides those effects on the control of physiological functions, numerous studies have highlighted the neuroprotective potential of PACAP in various neurological diseases involving neuronal cell death (17-20). For instance, PACAP protects dopaminergic neurons in a model of Parkinson's disease $(21,22)$, reduces amyloidopathy in a model of Alzheimer's disease (23-25), suppresses cortical damages in mice after traumatic brain injury (26), and improves memory performance in a model of Huntington's disease (27).

PACAP also decreases the infarct volume and improves functional recovery after stroke. One particularity of PACAP is that it counteracts many of the deleterious processes activated by stroke through its anti-excitotoxicity, anti-apoptotic, antiinflammatory, antioxidant, and immuno-modulatory activities (28-31). Furthermore, PACAP may act beyond the acute phase of stroke by promoting neurogenesis, plasticity and angiogenesis $(32,33)$.

However, to consider possible clinical applications, several parameters remain to be clarified, such as the optimal administration route, the lower efficient dose and the therapeutic window of PACAP. The present study aimed to investigate some of these issues in 2 stroke animal models.

\section{MATERIAL AND METHODS}

\section{Animals}

Two-month-old C57BL/6 (27.3 \pm 2.3 g; Janvier Labs) male mice, kept in a humidity- and temperature-controlled environment under an established photoperiod with free access to food and water, were used in this study. Experiments were approved by the regional committee of ethics for animal experimentation (CENOMEXA; approval number \#7619-2016101417048165) and conducted in an accredited animal facility (C7645104), 
according to the recommendations of the European Union under the supervision of authorized investigators.

\section{Reagents}

PACAP38 was synthesized using solid phase strategy combined with the Fmoc chemistry methodology as previously described (34). For administration, PACAP was dissolved in a $0.9 \%$ $\mathrm{NaCl}$ solution.

\section{tMCAO and PMCAO Chirurgical Procedures}

Occlusion was performed on the MCA, because approximately $70 \%$ of the human ischemic strokes affect this artery (10).

Transient middle cerebral artery occlusion (tMCAO) was induced under general anesthesia (isoflurane $1.5 \%$ to $2 \%$ infused by air) by occlusion of the right MCA by the mean of the intraluminal filament technique (35). Briefly, a nylon thread $(0.1 \mathrm{~mm}$ in diameter) with a distal cylinder (1 $\mathrm{mm}$ in length and $0.18 \mathrm{~mm}$ in diameter) was inserted into the lumen of the internal carotid artery and advanced to the origin of the MCA. The nylon thread was removed $45 \mathrm{~min}$ later to allow reperfusion. To monitor the occlusion, a laser-Doppler flowmeter probe (0.7 $\mathrm{mm}$ in diameter, FloLab Moor Instruments) was positioned and glued on the right parietal bone, after skin and muscle incision, and then CBF was measured continuously before the occlusion and up to $10 \mathrm{~min}$ after reperfusion in order to monitor the efficiency of the occlusion and success of the reperfusion. Based on those laser-Doppler flowmeter recordings, $11 \%$ of the operated animals were excluded from further analysis. For sham-operated animals, the nylon thread was put in place but not pushed to the origin of the MCA. Each treated mouse received $1 \mathrm{~h}$ after waking up and $24 \mathrm{~h}$ later, $500 \mu \mathrm{l}$ of $\mathrm{NaCl} 0.9 \%$ by subcutaneous injection to limit dehydration.

Permanent middle cerebral artery occlusion (pMCAO) was induced under general anesthesia (isoflurane $1.5 \%$ to $2 \%$ infused by air) using bipolar-forceps connected to a high frequency coagulation generator (KLS Martin ME 102). Briefly, skin was incised between the ear and the eye, the temporal muscle was detached from the skull without totally removing it and the MCA was localized below the transparent skull. The bone was carefully withdrawn above the artery. Once the MCA exposed, the artery was electrocoagulated with bipolar forceps. After checking the absence of recanalization, the temporal muscle was replaced and wound sutured. No electrocoagulation was performed on sham operated mice.

Following MCAO, mice were randomized in 3 groups, i.e., $\mathrm{NaCl}$ group (composed of ischemic mice treated with $0.9 \%$ $\mathrm{NaCl}$ ), a Sham group (composed of mice having undergone all the surgical procedure but without occlusion of the MCA and treated with $0.9 \% \mathrm{NaCl}$ ) and a PACAP group (composed of ischemic mice treated with various concentrations of PACAP according to the different protocols).

Behavioral tests were performed 2 and 8 days after stroke. Brains were collected at different time points in order to perform histological experiments to measure infarct volumes and/or to quantify gene expression.

\section{PACAP Administration Routes}

After tMCAO, mice were randomized into four groups corresponding to the different types of treatment: $\mathrm{NaCl}$ group (control), IV group, IP group, and IN group. Ten minutes after reperfusion, mice from the control group (Ctrl, $\mathrm{n}=8$ ) received $200 \mu \mathrm{l}$ of $\mathrm{NaCl}$ intravenously; those from the IV group (IV, $\mathrm{n}=7$ ) received $200 \mu \mathrm{l}$ of PACAP at the concentration of $0.02 \mu \mathrm{g} / \mathrm{kg}$ with $50 \%$ of the dose given as a bolus while the rest was provided as a 30-min infusion; those from the intraperitoneal (IP) group (IP, $\mathrm{n}=8$ ) received $200 \mu \mathrm{l}$ of PACAP as a bolus at a concentration of $0.02 \mu \mathrm{g} / \mathrm{kg}$; and finally those from the intranasal (IN) group (IN, $\mathrm{n}=7$ ) received $10 \mu \mathrm{l}$ of PACAP solution at a concentration of $1 \mu \mathrm{g} / \mu \mathrm{l}$. Forty-eight hours after reperfusion brains were collected for morphological analysis and gene expression studies (Scheme 1). The choice of these doses was based on the most efficient dose reported by Dejda et al. for IV injection (28) and the one used by Rat et al. for IN administration (23).

\section{PACAP Therapeutic Window}

After tMCAO, mice were randomized into five groups corresponding to the different times of treatment after stroke: a $\mathrm{NaCl}$ group who received $10 \mu \mathrm{l}$ of $\mathrm{NaCl}$ intranasally 10 min after reperfusion and 4 groups who received $10 \mu \mathrm{l}$ of PACAP at a concentration of $1 \mu \mathrm{g} / \mu \mathrm{l}$ intranasally $10 \mathrm{~min}, 1 \mathrm{~h}, 6 \mathrm{~h}$, or $15 \mathrm{~h}$

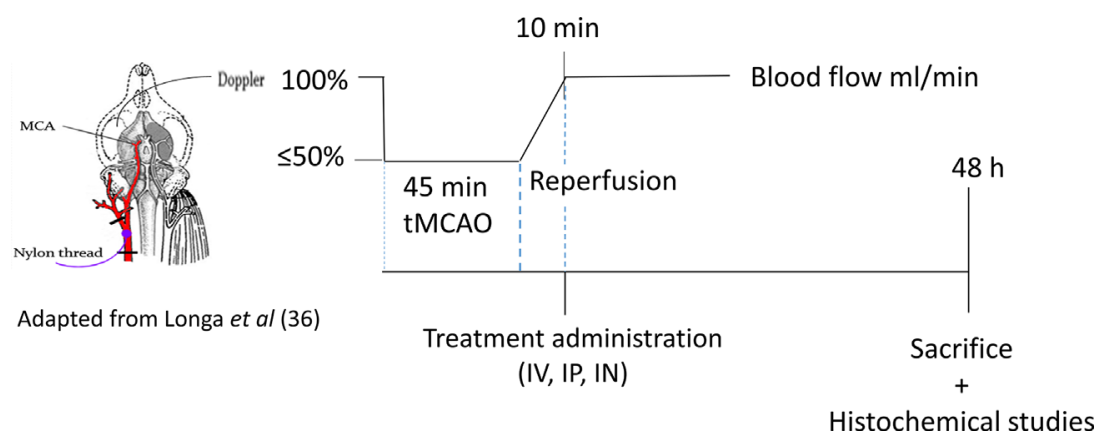

SCHEME 1 | The schema of PACAP administration routes. 
after reperfusion. Forty-eight hours after reperfusion brains were collected for further analysis (Scheme 2).

\section{PACAP Dose Response Efficiency}

Animals were divided into $\mathrm{NaCl}$, Sham and PACAP groups. PACAP animals were treated with 4 different concentrations of peptide ranging from $1 \mu \mathrm{g} / \mu \mathrm{l}$ to $1 \mathrm{fg} / \mu \mathrm{l}$. Excepted sham animals, all other mice were subjected to permanent occlusion of the middle cerebral artery (pMCAO). One hour after cerebral ischemia animals received a single IN administration of $10 \mu \mathrm{l}$ of PACAP or Nacl. Behavioral studies were conducted $48 \mathrm{~h}$ after treatment, just before animals were sacrificed and brains collected (Scheme 3).

\section{PACAP Delayed IN Daily Administration Efficiency}

To determine whether delayed IN delivery of PACAP durably improves functional recovery after cerebral ischemia, mice received, $6 \mathrm{~h}$ after pMCAO, an IN injection of a $0.9 \% \mathrm{NaCl}$ solution (control, sham) or of a PACAP solution ( $1 \mu \mathrm{g} / \mu \mathrm{l}$ or $1 \mathrm{ng} /$ $\mu \mathrm{l})$. Such IN administration was repeated daily until day 6 (D6).

Behavioral studies were performed $48 \mathrm{~h}$ (on day 2; D2) and $192 \mathrm{~h}$ (on day 8; D8) after pMCAO. The animals were sacrificed on day 8 and brains collected (Scheme 4).

\section{Functional Recovery Assessment}

The walking fault test was used to detect deficits in motor skills and balance (36). In this test, the mouse had to walk across an elevated wooden beam ( $1 \mathrm{~m}$ long and $9 \mathrm{~mm}$ of diameter) to reach a safe platform (home cage). The time to cross the beam and the number of walking faults were scored. The adhesive removal test was used to assess sensorimotor deficits (37). Performance on this test was quantified by measuring the time taken by the mouse to detect the presence of the adhesive (first contact) and the time taken by the mouse to remove it from both paws.

\section{Infarct Volume Measurement}

After sacrifice, brains were collected and frozen in cooled isopentane for cryosectionning. Twenty-micron thick sections were mounted on slides and stained with cresyl violet according to the Kapelsohn's method. The slides were scanned and the measurement of infarct volume was performed by using ImageJ program. Infarct volumes were then calculated as follows:

$$
v_{c}=v_{i}\left[v_{i}-\left(\frac{v_{i h}}{v_{i h}}-v_{\mathrm{ch}}\right)\right]
$$

$v_{c}$, corrected volume; $v_{i}$, infarct volume; $v_{i h}$, ipsilateral hemisphere volume; and $v_{\mathrm{ch}}$, controlateral hemisphere volume.

Animal Weight Monitoring and Food Intake Animals body weight was assessed before MCAO surgery (day 0) and then daily until sacrifice. For the food intake experiments, animals have been fasted overnight. After $\mathrm{NaCl}$ or PACAP (10 $\mu \mathrm{g} / \mu \mathrm{l})$ IN administration, pre-weighted pellets were provided and then food consumption was recorded every $30 \mathrm{~min}$ for $3 \mathrm{~h}$ using metabolic cages.

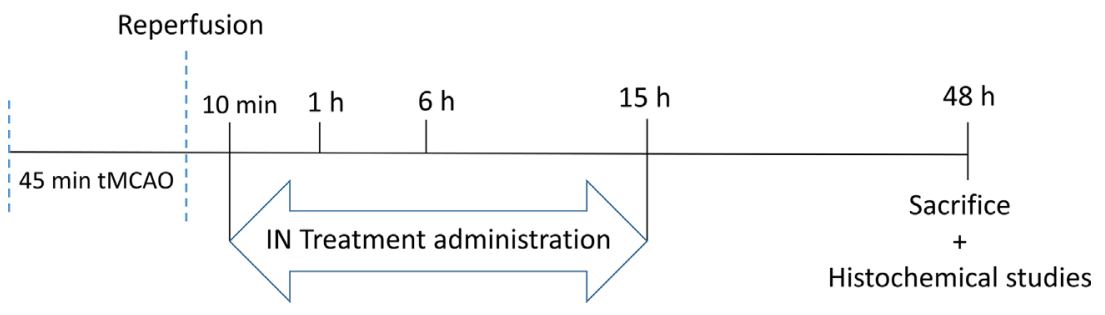

SCHEME 2 | The schema of PACAP therpauetic window.

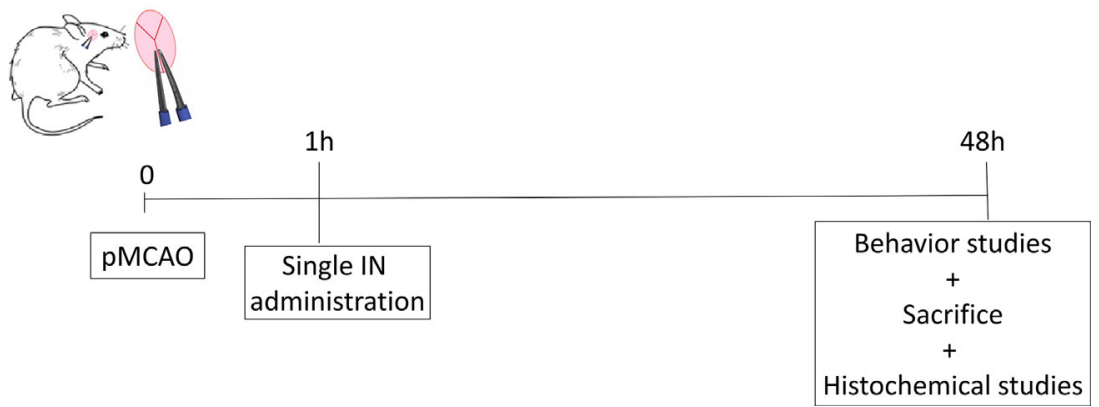

SCHEME 3 | The schema of PACAP dose response efficiency. 


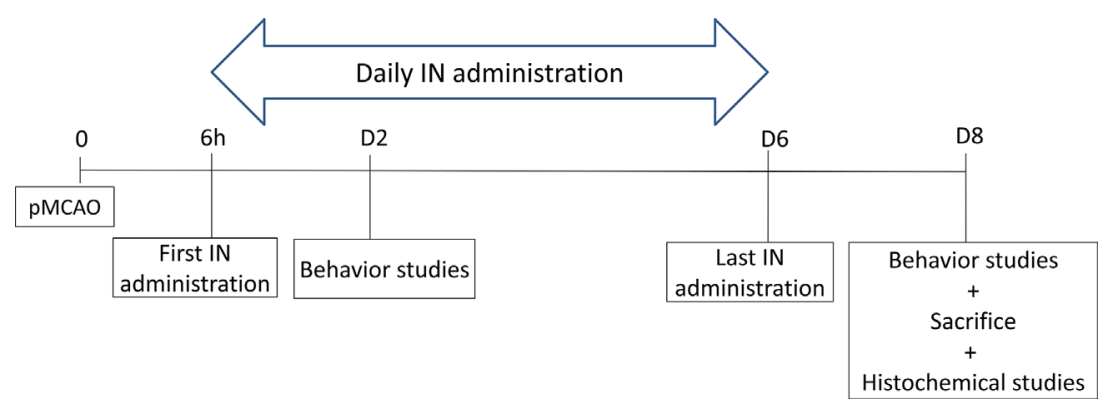

SCHEME 4 | The schema of PACAP delayed IN daily administration efficiency.

\section{Gene Expression Analysis (qPCR)}

Some brain tissue from ipsilateral hemispheres was collected from a series of crysotat's brain sections $(20-\mu \mathrm{m}$ thick) in TRIreagent (Sigma) and RNAs were extracted according to the manufacturer's protocol. RNAs were further purified with the NucleoSpin ${ }^{\circledR}$ RNA II kit (Macherey-Nagel) and total RNAs were reverse transcribed into cDNA with the Promega ${ }^{\circledR}$ ImProm-II Reverse Transcription System kit. Real-time polymerase chain reaction was performed on a QuantStudio $12 \mathrm{~K}$ Flex (Life Technologies) to quantify the expression of genes potentially regulated by ischemia.

\section{Statistical Analysis}

Results are expressed as mean \pm SEM ( $n \geq 6$ animals per group). We used ANOVA tests followed by post hoc tests for statistical analysis thanks to GraphPad Prism 6. A value of $P^{*}<0.05$ was considered as significant.

\section{RESULTS}

\section{PACAP Administration Route}

In the present study, the efficiency of IV administration, which has already been used in previous stroke studies (28-39), was compared with IP and IN administration routes. The results show that PACAP IN administration 10 min after reperfusion induced a three-fold reduction of the infarct volume (Figure 1A). This neuroprotective action of a PACAP IN delivery was much more efficient than the IV treatment, while the IP administration had no effect (Figure 1B).

\section{PACAP Therapeutic Window}

In a second step, the neuroprotective effect of a delayed single IN PACAP administration $10 \mathrm{~min}, 1 \mathrm{~h}, 6 \mathrm{~h}$ and $15 \mathrm{~h}$ after reperfusion was investigated in a $\mathrm{TMCAO}$ mice model. Those experiments were conducted using a single IN administration of $10 \mu \mathrm{l}$ of PACAP at a concentration of $1 \mu \mathrm{g} / \mu \mathrm{l}$, which was, as indicated in Figure 1B the most efficient. The results show that $10 \mu \mathrm{l}$ of PACAP at a concentration of $1 \mu \mathrm{g} / \mu \mathrm{l}$ induced $48 \mathrm{~h}$ after the occlusion a decrease of the lesioned volume of $72.8 \%, 38.7 \%$, and $22.1 \%$ compared to $\mathrm{NaCl}$ treated animals when administered
$10 \mathrm{~min}, 1 \mathrm{~h}$, or $6 \mathrm{~h}$ after reperfusion, respectively (Figure 1C). In contrast, when IN administration of PACAP was conducted $15 \mathrm{~h}$ after reperfusion, the peptide had no more effect.

\section{Gene Expression (qPCR)}

Stroke is a complex multifunctional physiopathology and MCAO activates a diversity of cellular and molecular mechanisms related to excitotoxicity, oxidative stress, post-ischemic inflammation and apoptosis $(40,41)$. To analyse and compare the different mechanisms potentially involved in the effects of PACAP IN administration $10 \mathrm{~min}, 1 \mathrm{~h}, 6 \mathrm{~h}$, and $15 \mathrm{~h}$ after reperfusion in a tMCAO mice model, a transcriptomic analysis was performed by measuring the expression of 88 genes known to be regulated after stroke. Among them, 42 were indeed regulated $48 \mathrm{~h}$ after tMCAO in one of the experimental conditions (Table 1). The results indicate that $64 \%$ of these 42 genes were regulated by stroke with only 4 genes repressed, all the others being increased. Among the 27 genes regulated by stroke, $89 \%$ were also regulated by PACAP after stroke in an opposite manner, showing that the peptide exerts a strong antiexcitotoxicity, antioxidant, anti-inflammatory, and antiapoptotic effect as evidenced by its ability to inhibit the expression of genes such as GJB6, NOS-1, IL6, BCL10, and caspase-9 (CASP9) which were induced by stroke. On the opposite, PACAP could counteract the decrease of genes such as Vegfa involved in vascular remodelling after stroke. PACAP also upregulated the brain expression of 15 genes not affected by stroke such as NEUROD1 or BDNF but known to promote synaptic plasticity and which contribute to improve functional recovery. Among the 42 genes of our list, only 4 were not regulated by PACAP, 24 being regulated when PACAP was injected $10 \mathrm{~min}$ after reperfusion, 18 when PACAP was injected $1 \mathrm{~h}$ after reperfusion, 19 when PACAP was injected $6 \mathrm{~h}$ after reperfusion and 17 when PACAP was injected $15 \mathrm{~h}$ after reperfusion. This highlights that most genes were regulated at different time points of PACAP treatment even if an early injection of PACAP after stroke affects more genes. Some genes such as CASP9, Tpa, or IL6 are regulated by PACAP regardless when the peptide is administered. Few genes such as Homer 1, not affected by PACAP at early times of treatment can be regulated when the peptide is administered in a delayed 
A

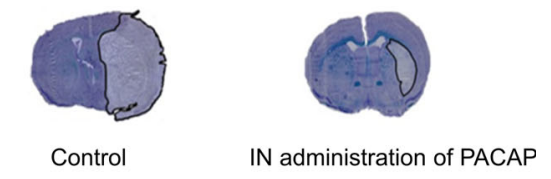

B

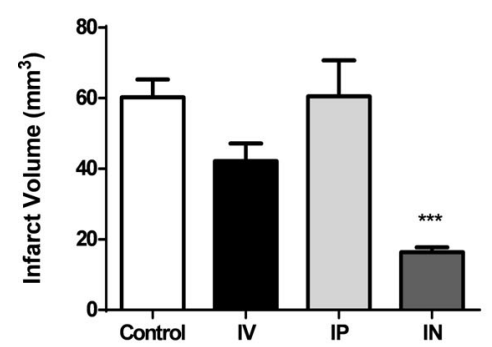

C

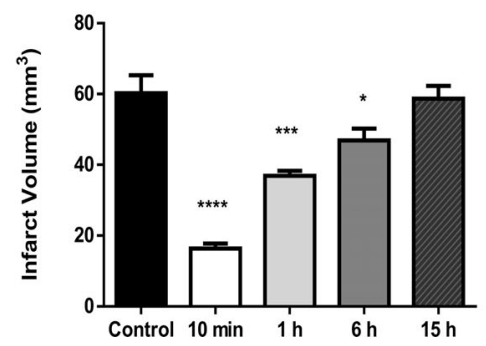

FIGURE 1 | Effect on cerebral infarct volume of PACAP administration 2 days after IMCAO. (A) Illustration of the brain infarct area after $\mathrm{NaCl}$ (Control) or PACAP (IN administration of PACAP) intranasal administration, $48 \mathrm{~h}$ after tMCAO. (B) Quantification of the brain infarct volume of mice treated $10 \mathrm{~min}$ after the reperfusion by intranasal administration of $\mathrm{NaCl}(0.9 \%$; Ctrl; $n=7)$, intravenous administration of PACAP $(200 \mu \mathrm{l}$ at a concentration of $0.02 \mu \mathrm{g} / \mathrm{kg}$ with $100 \mu \mathrm{l}$ in the form of a bolus and then $100 \mu \mathrm{l}$ by infusion over a 30-min period; IV; $n=7)$, intraperiotoneal administration of PACAP $(200 \mu \mathrm{l}$ in the form of a bolus at a concentration of $0.02 \mu \mathrm{g} / \mathrm{kg} ; \mathrm{IP} ; \mathrm{n}=8$ ) or intranasal administration of PACAP (10 $\mu$ in $10 \mu ; ; I N ; n=7), 48 \mathrm{~h}$ after a 45 -min tMCAO. (C) Quantification of the brain infarct volume of mice treated 10 min $(n=8), 1 \mathrm{~h}(\mathrm{n}=8), 6 \mathrm{~h}(\mathrm{n}=8)$ or $15 \mathrm{~h}(\mathrm{n}=7)$ after reperfusion by an intranasal administration of PACAP (10 $\mu \mathrm{g}$ in $10 \mu \mathrm{l}$; IN). Control animals (Ctrl; $\mathrm{n}=7$ ) received $10 \mu \mathrm{l} \mathrm{NaCl} 0.9 \% \mathrm{IN}$ administration. Volume was expressed in $\mathrm{mm}^{3}$. ANOVA followed by the Bonferroni's test. ${ }^{*} P<0.05$; ${ }^{\star \star *} P<0.001$; ${ }^{\star \star \star \star} P<0.0001$ vs. Ctrl.

manner and vice versa, few genes such as Hmox1 or Gjd2 are only regulated by PACAP when it is administered to the animals just after the reperfusion.

\section{PACAP Dose Response Efficiency}

After putting in evidence the efficiency of an IN administration of PACAP for stroke treatment and the existence of a therapeutic window of a least $6 \mathrm{~h}$ in the tMCAO mice model, we looked for the most efficient dose of the peptide. For those experiments, the neuroprotective effect of a single IN administration of different concentrations of PACAP ranging from $1 \mu \mathrm{g} / \mu \mathrm{l}$ to $1 \mathrm{fg} / \mu \mathrm{l}, 1 \mathrm{~h}$ after permanent middle cerebral artery occlusion (pMCAO) was tested. The choice of using a pMCAO mice model was both to evaluate the efficiency of the treatment in another commonly used stroke model as recommended by the STAIR guidelines and to reduce the number of animals used, given that reproducibility and survival rate in the pMCAO is higher than in the tMCAO. Effectively we recorded that the mortality rate in tMCAO model (20\%) was approximately twice higher than in the pMCAO one. The other advantage of the pMCAO model is that it produces a smaller infarct area more in line with what is observed in human stroke (42). Results highlight that a single IN administration of very low concentrations of PACAP decreased infarct volume (Figures 2A, B) when administered $1 \mathrm{~h}$ after stroke in a pMCAO mice model. Effectively, $48 \mathrm{~h}$ after the occlusion, an $86.3 \%$ reduction of the infarct volume compared to controls was observed when animals received $1 \mu \mathrm{g} / \mu \mathrm{l}$ IN PACAP treatment (Figures 2A, B). This protection diminished when decreasing the doses of PACAP, with a reduction of the infarct volume of only $24.6 \%$ for animals receiving $1 \mathrm{fg} / \mu \mathrm{l}$ of PACAP (Figure 2B). In addition, to these histological effects, PACAP also improved functional recovery (Figures 2C, D). In particular, PACAP administered $1 \mathrm{~h}$ after pMCAO decreased the number of slips from $16.3 \pm 0.6$ for control mice to $6.6 \pm 0.3$ for animals treated with the highest concentration of PACAP (Figure 2C). PACAP also reduced the time spent to cross the beam from $29.6 \pm 0.9 \mathrm{~s}$ for control mice to $18 \pm 1.6 \mathrm{~s}$ for animals treated with $1 \mu \mathrm{g} / \mu \mathrm{l}$ PACAP. Finally, PACAP treatment enhanced performances in the adhesive removal test compared to control animals after pMCAO with asymmetrical symptoms (Figure 2D). It is interesting to note that several of those tests revealed functional improvement even with the lowest doses of PACAP (Figures 2C, D).

\section{PACAP Delayed IN Daily Administration Efficiency}

The efficacy of an IN administration of PACAP at very low doses in a $\mathrm{pMCAO}$ mice model being demonstrated, we tested whether the treatment is still efficient and persistent when started $6 \mathrm{~h}$ after ischemia in the pMCAO mice model. For those experiments, animals received $1 \mu \mathrm{g} / \mu \mathrm{l}$ or $1 \mathrm{ng} / \mu \mathrm{l}$ daily administration of PACAP. The results show that at day 8 , the infarct volume of $3.8 \pm 0.5 \mathrm{~mm}^{3}$ for mice from the control group was reduced to $2.6 \pm 0.6$ and $1.5 \pm 0.2 \mathrm{~mm}^{3}$ for animals treated intranasally with $1 \mu \mathrm{g} / \mu \mathrm{l}$ and $1 \mathrm{ng} / \mu \mathrm{l}$ of PACAP, respectively (Figures 3A, B). Such treatments also improved the sensorimotor performances by reducing on the beam test, the number of slips and the time spent to cross the beam both 2 and 8 days after the ischemia (Figures 3C, D) and by reducing for the adhesive removal test, the time spent to feel the presence of the adhesive and to withdraw it from both forepaws (Figures 3E, F). In most pMCAO mice, an asymmetrical symptom was observed with firstly withdrawal of the adhesive from the right paw, which is 
TABLE 1 | Effect of acute and delayed IN PACAP administration after reperfusion (tMCAO protocol) on gene expression measured $48 \mathrm{~h}$ after the occlusion.

\begin{tabular}{|c|c|c|c|c|c|c|c|c|c|c|c|c|c|c|c|c|}
\hline \multirow[t]{2}{*}{ Events } & \multirow[t]{2}{*}{ Gene } & \multicolumn{3}{|c|}{ ctrl vs sham } & \multicolumn{3}{|c|}{$10 \mathrm{~min}$ vs ctrl } & \multicolumn{3}{|c|}{$1 \mathrm{~h}$ vs ctrl } & \multicolumn{3}{|c|}{$6 \mathrm{~h}$ vs ctrl } & \multicolumn{3}{|c|}{$15 \mathrm{~h}$ vs ctrl } \\
\hline & & & SEM & stat & & SEM & stat & & SEM & stat & & SEM & stat & & SEM & stat \\
\hline \multirow[t]{3}{*}{ Excitotoxicity } & GJD2 & $\searrow 0.22$ & 0.09 & $\star \star \star *$ & $\nearrow 7.88$ & 0.19 & $\star \star \star \star \star ~$ & $\nearrow 1.83$ & 0.1 & & $\nearrow 1.01$ & 0.05 & & $\nearrow 1.66$ & 0.12 & \\
\hline & GJB6 & 1.29 & 0.06 & $\star *$ & $\searrow 0.34$ & 0.07 & 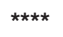 & $\searrow 0.72$ & 0.12 & $\star \star \star$ & $\nearrow 1.45$ & 0.34 & & $\nearrow 1.26$ & 0.14 & \\
\hline & GAD1 & $\searrow 0.88$ & 0.19 & & $\searrow 0.378$ & 0.44 & & 2.49 & 0.21 & $\star \star$ & フ2.13 & 0.14 & * & フ2.52 & 0.28 & $\star \star$ \\
\hline \multirow[t]{8}{*}{ Stress Response } & CAT & $\nearrow 1.56$ & 0.38 & & $\searrow 0.80$ & 0.03 & $\star * *$ & $\searrow 0.30$ & 0.13 & $\star *$ & $\nearrow 1.04$ & 0.14 & & $\searrow 0.40$ & 0.09 & $\star \star$ \\
\hline & GPX1 & $\nearrow 1.78$ & 0.34 & * & $\searrow 0.58$ & 0.4 & & $\searrow 0.10$ & 0.32 & & $\nearrow 1.157$ & 0.17 & & $\searrow 0.61$ & 0.07 & \\
\hline & NOS1 & フ2.26 & 0.18 & $\star *$ & $\searrow 0.46$ & 0.21 & $* *$ & $\searrow 0.50$ & 0.14 & $\star *$ & $\searrow 0.54$ & 0.22 & $\star *$ & $\searrow 0.58$ & 0.19 & * \\
\hline & HMOX1 & $\nearrow 19.55$ & 1.25 & 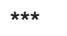 & $\searrow 0.47$ & 0.49 & $\star *$ & $\searrow 0.84$ & 3.57 & & $\searrow 0.87$ & 1.52 & & $\nearrow 1.02$ & 2.97 & \\
\hline & JUN & $\nearrow 1.53$ & 0.26 & * & $\searrow 0.83$ & 0.19 & & $\searrow 0.30$ & 0.14 & & $\searrow 0.87$ & 0.31 & & $\searrow 0.53$ & 0.06 & $\star \star$ \\
\hline & HSPA1B & /3.20 & 0.43 & * & $\searrow 0.40$ & 0.53 & & $\searrow 0.42$ & 0.1 & & $\searrow 0.92$ & 0.58 & & $\searrow 0.61$ & 0.38 & \\
\hline & HSPB1 & $\nearrow 4.42$ & 0.64 & ** & $\searrow 0.77$ & 0.93 & & $\nearrow 1.04$ & 0.45 & & $\nearrow 1.09$ & 0.44 & & $\searrow 0.72$ & 0.58 & \\
\hline & HSPD1 & $\nearrow 2.04$ & 0.06 & * & $\searrow 0.73$ & 0.14 & * & $\searrow 0.59$ & 0.16 & & $\searrow 0.81$ & 0.31 & & $\searrow 0.87$ & 0.27 & \\
\hline \multirow[t]{8}{*}{ Apoptosis } & DDIT3 & $\searrow 0.78$ & 0.23 & & $\nearrow 1.05$ & 0.23 & & $\nearrow 1.11$ & 0.16 & & フ2.18 & 0.09 & ** & $\searrow 0.844$ & 0.25 & \\
\hline & DUSP6 & $\searrow 0.75$ & 0.26 & & $\nearrow 1.73$ & 0.41 & & $\nearrow 2.56$ & 0.36 & * & $\nearrow 2.72$ & 0.34 & * & $\nearrow 1.66$ & 0.2 & \\
\hline & BCL10 & 71.90 & 0.05 & * & $\searrow 0.65$ & 0.31 & & $\searrow 0.993$ & 0.12 & & $\searrow 0.17$ & 0.03 & $\star \star \star$ & $\searrow 0.81$ & 0.22 & \\
\hline & FAS & $\nearrow 1.31$ & 0.18 & & /2.89 & 0.21 & * & フ3.39 & 0.65 & $\star *$ & $\nearrow 2.34$ & 0.26 & & $\nearrow 1.80$ & 0.27 & \\
\hline & CASP9 & $\nearrow 2.21$ & 0.08 & 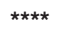 & $\searrow 0.34$ & 0.02 & 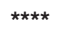 & $\searrow 0.50$ & 0.09 & $\star * *$ & $\searrow 0.10$ & 0.04 & 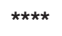 & $\searrow 0.49$ & 0.2 & $\star \star *$ \\
\hline & GADD45A & $\searrow 0.63$ & 0.42 & & フ2.34 & 0.19 & $\star \star$ & T2.90 & 0.24 & $\star \star *$ & $\searrow 0.90$ & 0.04 & & $\nearrow 1.97$ & 0.15 & * \\
\hline & ATF3 & $\nearrow 37.34$ & 2.24 & $\star *$ & $\searrow 0.16$ & 0.07 & * & $\nearrow 2.64$ & 4.2 & $\star \star \star$ & $\nearrow 1.04$ & 8.65 & & $\nearrow 1.16$ & 2.82 & \\
\hline & PIK3R1 & $\nearrow 1.05$ & 0.11 & & $\searrow 0.78$ & 0.27 & & $\searrow 0.36$ & 0.07 & $\star \star$ & $\nearrow 1.10$ & 0.13 & & $\searrow 0.65$ & 0.09 & \\
\hline \multirow[t]{9}{*}{ Inflammation } & IL12A & $\nearrow 2.20$ & 0.64 & & $\searrow 0.49$ & 0.55 & & $\searrow 0.92$ & 0.41 & & $\searrow 0.24$ & 0.14 & * & $\searrow 0.84$ & 0.2 & \\
\hline & IL6 & 74.68 & 0.1 & $\star * * *$ & $\searrow 0.23$ & 0.05 & 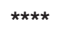 & $\searrow 0.445$ & 0.24 & 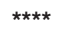 & $\searrow 0.16$ & 0.15 & $\star \star \star \star *$ & $\searrow 0.33$ & 0.52 & $\star \star \star * \star$ \\
\hline & IFNAR1 & \3.87 & 0.34 & * & $\searrow 0.12$ & 0.06 & * & $\searrow 0.63$ & 0.32 & & $\searrow 0.27$ & 0.13 & * & $\searrow 0.48$ & 0.85 & \\
\hline & IRF1 & $\nearrow 2.74$ & 0.52 & $* *$ & $\searrow 0.49$ & 0.17 & * & $\searrow 0.47$ & 0.18 & $\star *$ & $\nearrow 1.11$ & 0.26 & & $\searrow 0.43$ & 0.21 & $\star *$ \\
\hline & IRF5A & フ3.66 & 0.94 & * & $\searrow 0.51$ & 0.07 & * & $\searrow 0.73$ & 0.98 & & $\nearrow 1.48$ & 0.58 & & $\searrow 0.44$ & 0.27 & \\
\hline & CXCR4 & $\pi .47$ & 0.47 & $* * *$ & $\searrow 0.44$ & 0.50 & * & $\searrow 0.458$ & 0.37 & * & $\nearrow 1.09$ & 0.57 & & $\searrow 0.46$ & 0.53 & * \\
\hline & CXCR1 & $\nearrow 1.03$ & 0.08 & & $\searrow 0.95$ & 0.02 & & フ1.59 & 0.24 & & $\nearrow 1.99$ & 0.44 & * & $\nearrow 1.47$ & 0.14 & \\
\hline & VCAM1 & $\searrow 0.60$ & 0.57 & & $\nearrow 1.71$ & 0.48 & & $\nearrow 1.47$ & 0.2 & * & $\nearrow 1.51$ & 0.08 & & $\nearrow 1.96$ & 0.13 & $* *$ \\
\hline & TLR4 & $\nearrow 4.06$ & 0.33 & 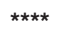 & $\searrow 0.58$ & 0.28 & $\star *$ & $\searrow 0.78$ & 0.03 & * & $\searrow 0.85$ & 0.39 & & $\searrow 0.52$ & 0.23 & $\star \star \star \star *$ \\
\hline \multirow{14}{*}{$\begin{array}{l}\text { Synaptic/neurogenesis/Angiogenesis/ } \\
\text { cellular protection and activity }\end{array}$} & NEUROD1 & $\searrow 0.48$ & 0.55 & & $\nearrow 2.07$ & 0.32 & $\star *$ & $\nearrow 1.08$ & 0.1 & & $\nearrow 2.28$ & 0.1 & * & $\nearrow 1.32$ & 0.04 & \\
\hline & BDNF & $\searrow 0.52$ & 0.39 & & $\nearrow 1.33$ & 0.12 & & $\nearrow 6.07$ & 0.95 & & $\nearrow 3.31$ & 0.21 & $\star *$ & $\nearrow 1.35$ & 0.18 & \\
\hline & SLC16A7 & $\searrow 0.74$ & 0.18 & & $\searrow 0.20$ & 0.03 & & $\searrow 0.60$ & 0.16 & & $\searrow 0.99$ & 0.21 & & $\nearrow 1.91$ & 0.18 & * \\
\hline & $\mathrm{DBI}$ & $\searrow 0.37$ & 0.06 & $* *$ & $\nearrow 2.83$ & 0.46 & * & $\searrow 0.99$ & 0.1 & & $\nearrow 1.26$ & 0.09 & & $\nearrow 1.53$ & 0.14 & \\
\hline & VEGFA & $\searrow 0.47$ & 0.15 & $* *$ & $\nearrow 1.75$ & 0.27 & $* *$ & $\nearrow 1.19$ & 0.1 & & $\nearrow 2.32$ & 0.08 & $\star * *$ & $\searrow 0.93$ & 0.07 & \\
\hline & TGFB2 & $\nearrow 1.02$ & 0.15 & & $\nearrow 1.55$ & 0.26 & & $\nearrow 1.17$ & 0.08 & & $\nearrow 1.27$ & 0.11 & & $\nearrow 1.76$ & 0.33 & * \\
\hline & TGFB1 & 76.46 & 0.66 & 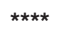 & $\searrow 0.40$ & 0.06 & $\star \star \star \star \star$ & $\searrow 0.49$ & 0.95 & $\star *$ & $\searrow 0.54$ & 0.47 & $\star \star \star$ & $\searrow 0.16$ & 0.32 & $\star \star \star \star *$ \\
\hline & TGFBR1 & $\nearrow 1.25$ & 0.17 & & $\nearrow 1.73$ & 0.52 & & $\nearrow 1.44$ & 0.08 & & 71.30 & 0.18 & & $\searrow 0.83$ & 0.24 & \\
\hline & GFAP & 721.61 & 3.71 & $\star * *$ & $\searrow 0.42$ & 1.03 & $\star \star$ & $\searrow 0.80$ & 3.13 & & $\searrow 0.86$ & 1.88 & & $\searrow 0.52$ & 3.46 & * \\
\hline & HOMER1 & $\searrow 0.27$ & 0.53 & * & $\searrow 0.17$ & 0.09 & & $\nearrow 1.72$ & 0.12 & & 3.59 & 0.25 & * & フ1.62 & 0.16 & \\
\hline & TIMP1 & $\nearrow 46.90$ & 8.63 & $\star \star *$ & $\searrow 0.75$ & 0.59 & & $\searrow 0.74$ & 2.56 & & $\searrow 0.36$ & 1.85 & $\star \star$ & $\searrow 0.456$ & 4.55 & * \\
\hline & TPA & フ7.95 & 0.57 & $\star \star \star \star \star ~$ & $\searrow 0.17$ & 0.03 & 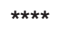 & $\searrow 0.52$ & 1.32 & $\star *$ & $\searrow 0.17$ & 0.21 & $\star \star *$ & $\searrow 0.334$ & 1.04 & $\star * \star$ \\
\hline & AQP4 & $\nearrow 2.86$ & 0.22 & $\star *$ & $\searrow 0.61$ & 0.23 & * & $\searrow 0.59$ & 0.19 & & $\searrow 0.43$ & 0.27 & * & $\searrow 0.95$ & 0.61 & \\
\hline & ACVR1 & $\nearrow 2.33$ & 0.22 & $\star *$ & $\searrow 0.34$ & 0.08 & $\star *$ & $\searrow 0.36$ & 0.23 & $\star *$ & $\searrow 0.28$ & 0.17 & $\star \star$ & $\searrow 0.36$ & 0.33 & \\
\hline
\end{tabular}

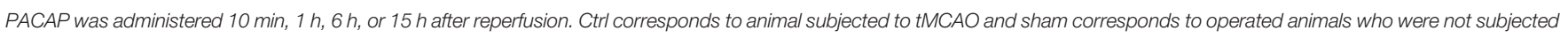
to $\mathrm{tMCAO}$. Results are expressed in relation to the ones of sham $\pm S E M .\left({ }^{*} P<0.05 ;{ }^{* *} P<0.01 ;{ }^{* * *} P<0.001 ;{ }^{* * * *} P<0.0001\right)$.

The arrow also indicate a up and down gene regulation.

controlled by the ipsilateral hemisphere, before elimination in a second time of the adhesive from the left paw, which is controlled by the contralateral hemisphere.

\section{Food Intake and Body Weight Variation}

The anorexigenic effects of PACAP have mainly been studied in various species such as chickens $(43)$, fishes $(44,45)$, and rodents $(46,47)$, using different routes of administration from systemic ones such as IV or IP to direct brain administrations such as ICV or amygdala central nucleus injections. In the present study the effect of IN administration of PACAP was evaluated on body weight variation and food intake. The results showed no significant differences between control and PACAP treated groups in terms of food intake (Figure 4A). Interestingly, weight loss was usually slightly less important after PACAP IN acute or delayed administration, 2 and 4 days after pMCAO (Figure 4B). A significant decrease in the weight loss was even observed in the pMCAO model after 8 days of $1 \mathrm{ng} / \mu \mathrm{l}$ PACAP daily IN administration. Those experiments also highlight that the weight loss is significantly more important for the mice subjected to a 
A

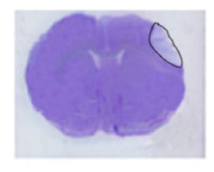

Control

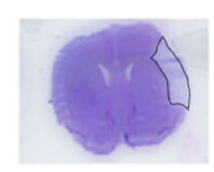

PACAP $1 \mu \mathrm{g} / \mu \mathrm{L}$

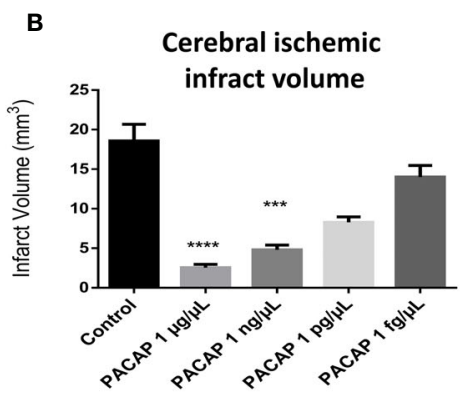

C
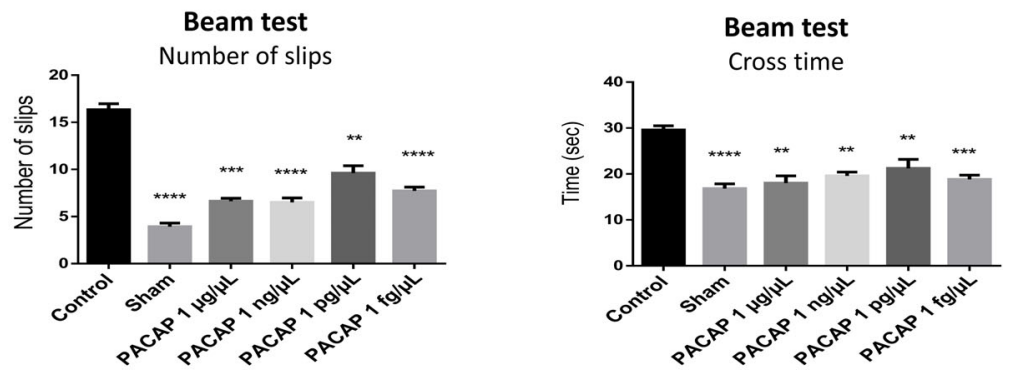

D

Adhesive removal test

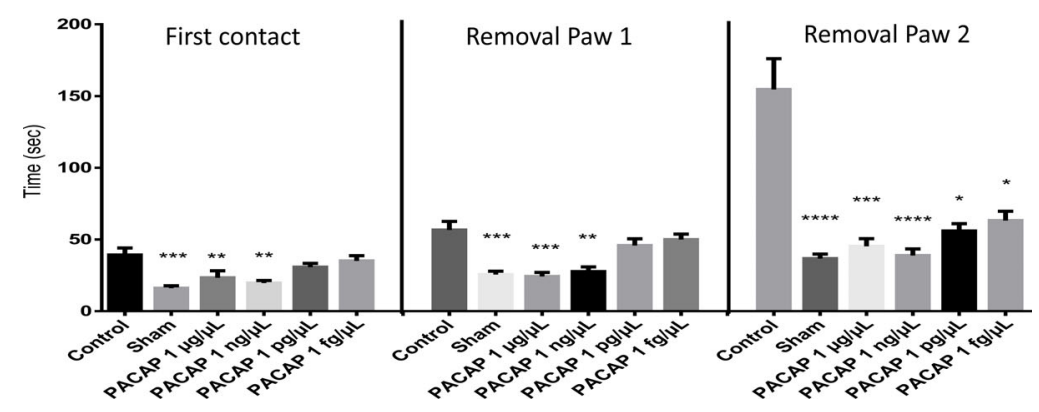

FIGURE 2 | Effects on the infarct volume and functional recovery, 2 days after stroke, of a single intranasal (IN) administration of decreasing concentrations of PACAP provided $1 \mathrm{~h}$ after pMCAO. Male C57BL6 mice were treated with a saline solution ( $\mathrm{NaCl} 0.9 \%$ for control and sham) or with $10 \mu \mathrm{l}$ of different PACAP concentrations ( $1 \mu \mathrm{g} / \mu \mathrm{l}, 1 \mathrm{ng} / \mu \mathrm{l}, 1 \mathrm{pg} / \mathrm{\mu l}$, and $1 \mathrm{fg} / \mu \mathrm{l}$ dissolved in $\mathrm{NaCl}$ 0.9\%). (A) llustration of the brain infarct zone after $\mathrm{NaCl}$ (Control) or PACAP $1 \mu \mathrm{g} / \mu \mathrm{l}$ IN administration, $48 \mathrm{~h}$ after pMCAO. (C) Cerebral ischemic infarct volume $\left(\mathrm{mm}^{3}\right) 48 \mathrm{~h}$ after pMCAO. (C) Beam test indicating cross times and number of slips of mice on 9-mm beam. (D) Adhesive removal test with the time taken for first contact and adhesive removal from mice paws 2 days after stroke. PACAP treatment promoted functional recovery and reduced cerebral ischemic lesions in stroke mice. Variations of $n \geq 6$ animals per group are reported as S.E.M. ( ${ }^{*} P<0.05$; $\left.{ }^{* *} \mathrm{P}<0.01 ;{ }^{* \star *} \mathrm{P}<0.001 ;{ }^{* \star \star} \mathrm{P}<0.0001\right)$.

tMCAO than for the animals included in the pMCAO protocol, which is probably due to the heavier surgery that represents the intraluminal filament technique, comforting the necessity to use various stroke models which have different outcomes that may interfere differently with the subsequent treatment.

\section{DISCUSSION}

Stroke is the second leading cause of death worldwide and the leading cause of disability in adults. The complex processes involved in stroke induced brain damages explain the difficulties to develop effective pharmacological agents, making it a major health problem. Thus so far, reperfusion is the only approach really recommended but its use is restricted because of cost, short therapeutic window or risks of causing a hemorrhage, so that it can only benefit to a small proportion of stroke victims. This therefore led over the last couple of years to intense research targeting some of the numerous mechanisms activated after brain artery occlusion such as excitotoxicity, oxidative stress, inflammation and apoptosis in order to block neuronal cell death and/or stimulate neurogenesis, synaptogenesis and angiogenesis in order to promote functional recovery. However, most trials so far have failed, probably because molecules could only target part of stroke induced deleterious pathways. In this context, PACAP may be a promising molecule as it could counteract most if not all the deleterious processes induced by stroke and improve functional 


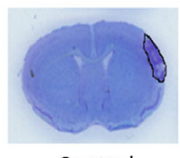

Control

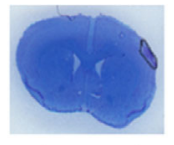

PACAP $1 \mu \mathrm{g} / \mu \mathrm{L}$

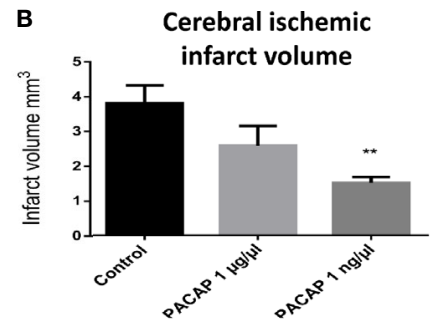

C

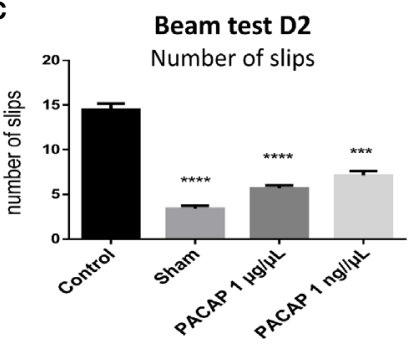

D

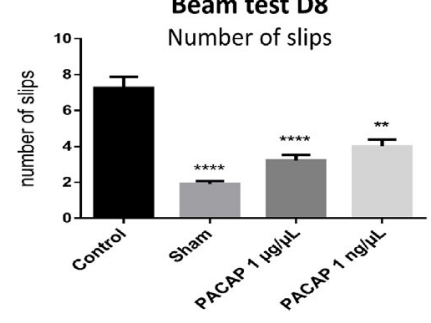

Beam test D2
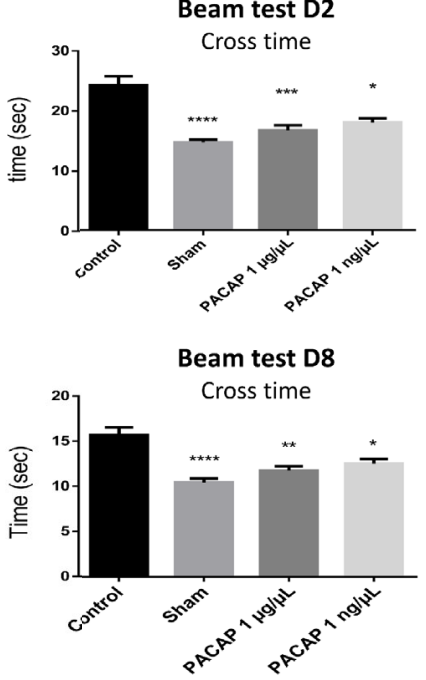

E

Adhesive removal test $\mathrm{D2}$

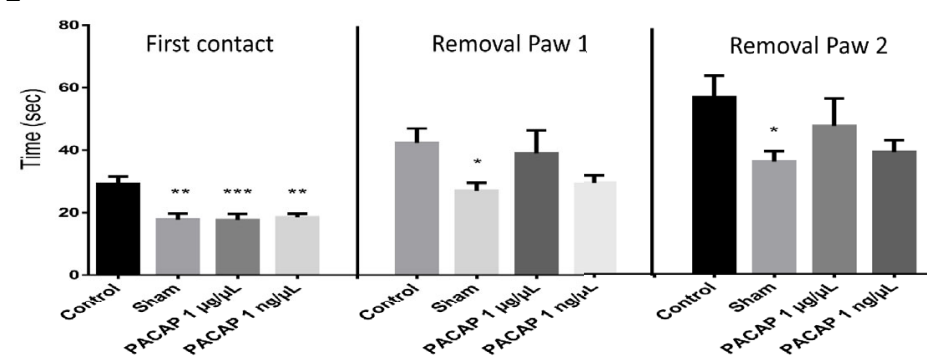

$\mathbf{F}$

Adhesive removal test $D 8$

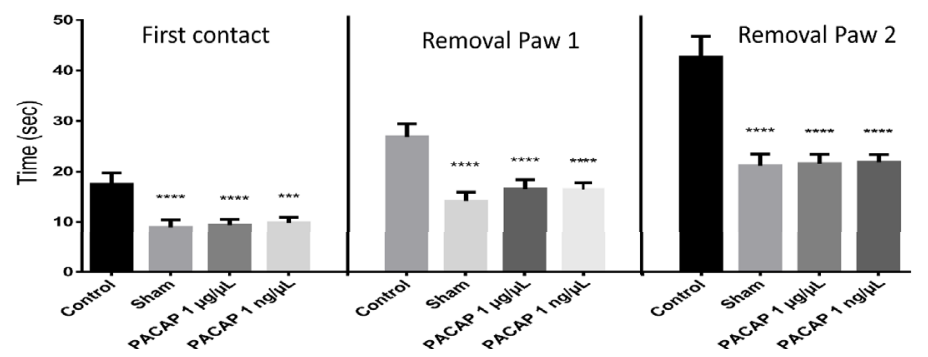

FIGURE 3 | Effects on the infarct volume and functional recovery of delayed ( $6 \mathrm{~h}$ post pMCAO) PACAP daily administration, 2 and 8 days after brain ischemia. Male C57BL6 mice were treated with a saline solution (control, sham) or with different concentrations of PACAP. (A) lllustration of the brain infarct zone after NaCl (control) or PACAP $1 \mu \mathrm{g} / \mu \mathrm{l}$ intranasal administration, 8 days after pMCAO. (B) Cerebral ischemic infarct volume $\left(\mathrm{mm}^{3}\right) 8$ days after pMCAO. (C, D) Beam test indicating cross times and number of slips of mice (sham and stroked animals) on $9 \mathrm{~mm}$ beam 2 and 8 days after stroke. (E, F) Adhesive removal test with the time taken for first contact and adhesive removal from mice paws 2 and 8 days after stroke. PACAP treatment promoted functional recovery and reduced cerebral ischemic lesions in stroke mice. Errors are reported as Mean \pm S.E.M and $n \geq 8$ animals per group. $\left({ }^{*} P<0.05 ;{ }^{* *} P<0.01 ;{ }^{* * *} P<0.001,{ }^{* \star * *} P<0.0001\right)$. 


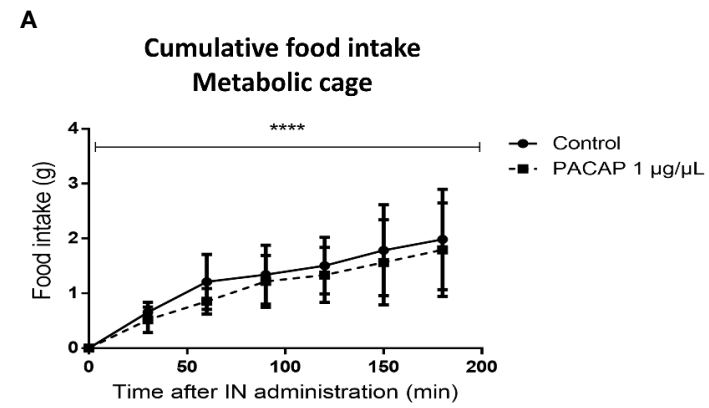

B1

Weight variation after $\mathrm{tMCAO}$ IV, IP and IN administration

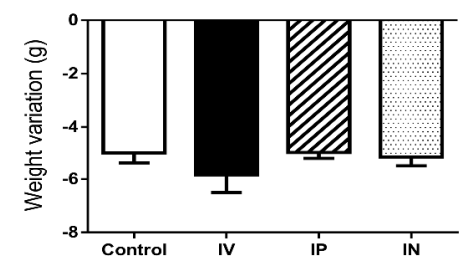

B3

Weight variation after PMCAO IN administration

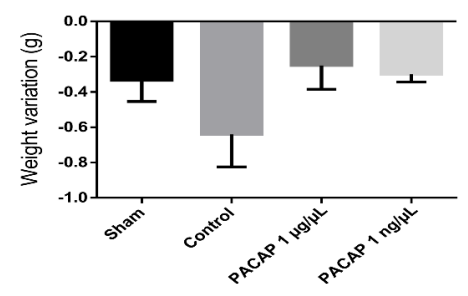

B2 Weight variation after tMCAO
IN administration

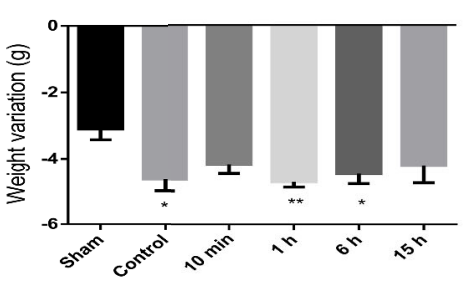

B4

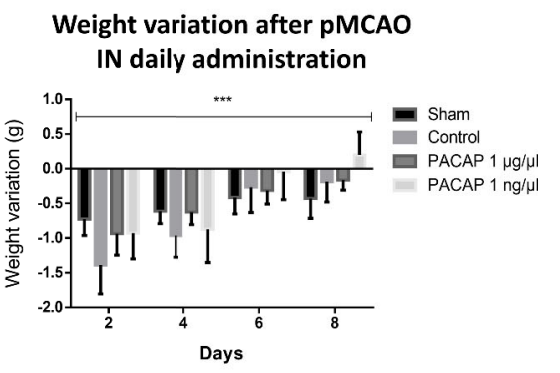

FIGURE 4 | Effects of stroke and/or PACAP treatment on cumulative food intake and body weight variation. (A) Cumulative food intake after PACAP IN delivery over $3 \mathrm{~h}$ of time in non-operated mice. (B) Variation of body weight after PACAP administration following different stroke protocols, i.e., PACAP administration routes protocol (B1.), PACAP therapeutic window protocol (B2.), PACAP dose response efficiency protocol (B3.) and PACAP delayed IN daily administration efficiency protocol (B4.). Errors are reported as Mean \pm S.E.M. $\left({ }^{\star} P<0.05 ;{ }^{\star \star} \mathrm{P}<0.01 ;{ }^{\star \star \star} \mathrm{P}<0.001\right)$. Two-way ANOVA was performed for figure A and $\mathrm{B} 4$ showing significant means only for time factor (minutes and days), while the effects of treatment and the interaction are not significant.

recovery in various MCAO models (39-48). However, to consider the use of PACAP in clinic, several points remain to be evaluated and/or improved. Indeed, PACAP, acting via 3 different receptors (PAC1, VPAC1, and VPAC2) widely distributed in the brain and peripheral organs, regulates numerous biological functions, including hormone release or systemic decrease of blood pressure. It seems to be the VPAC2 receptor, highly expressed in the cardiovascular system and endocrine glands that is at the origin of most of the deleterious side effects of PACAP. Conversely, VPAC2 expression is very low in the brain (14).

In addition, although PACAP remains active after IV administration by passing the blood-brain barrier (BBB), it is very quickly degraded in blood with a half-life of less than $5 \mathrm{~min}$ due to a high sensibility to dipeptidyl-peptidase-IV (DPP-IV), endopeptidases, and carboxypeptidases. In particular, PACAP is hydrolyzed into PACAP3-38 acid amins and PACAP5-38 to create a shorter peptide with antagonist activity which may limit the effect of the treatment $(34,49,50)$.

\section{PACAP Administration Routes}

Various administration routes of PACAP have already been reported from IP to intravitreal administration (16-51), leading either to systemic or topical delivery of the peptide. This diversity of PACAP administration routes led us to compare the efficiency of a single intranal (IN), IV, and IP administration of the peptide after tMCAO in $\mathrm{C} 57 \mathrm{Bl} / 6$ mice. The results 
revealed that the IN PACAP delivery led to the stronger neuroprotection, which could be explained by the fact that the quantity of PACAP able to reach the brain is variable, depending on i) the amount provided and ii) the route of administration. It is also likely that IN administration induces a direct delivery of PACAP to the brain through a rapid absorption via the nasal mucosa with highest uptake of the peptide in the occipital cortex and striatum (52). At the same time, IN delivery reduces systemic exposure, decreasing by the way peripheral side effects, in particular on the cardiovascular system.

\section{Food Intake and Weight Variation}

It is well established that PACAP regulates food intake and energy homeostasis through both central and peripheral action. In particular, PACAP injected centrally into the hypothalamic ventromedial nucleus or into the posterior region of the stria terminalis bed nucleus induced a rat weight loss $24 \mathrm{~h}$ post injection $(53,54)$. Also, an IP administration of PACAP to PAC1-deficient and wild-type mice shows that PACAP suppresses appetite via its PAC1 receptor by inhibiting ghrelin and increasing GLP-1 and leptin (55). The anorexigenic effect was also observed after IV and ICV administration of high concentrations of PACAP $(56,57)$. Although our results seem to be in contradiction with these previous reports, the discrepancy might be due to differences in the amount of PACAP which reaches the various brain regions after IN administration. It is estimated that less than $4 \%$ of the $10 \mu \mathrm{g}$ of PACAP administered to the mice actually reach the brain (52). Furthermore, the main brain area playing a role in appetite regulation and energy homeostasis are hypothalamus and amygdala $(58,59)$ while the IN administration tend to promote peptide uptake toward the occipital cortex and striatum (52). In addition to those experiments on food intake, further thorough tests must be done to confirm the innocuity of this efficient, non-invasive and easy to set up IN administration of PACAP $(60,61)$. Moreover, this approach has started to be used with PACAP for the treatment, in animal models, of some neurodegenerative diseases such as Alzheimer or Huntington (23, 27, 62).

\section{PACAP Therapeutic Window}

The present results demonstrate that the therapeutic window of PACAP in mice could exceed $6 \mathrm{~h}$. This observation is very promising when considering that $\mathrm{rtPA}$, the approved medical treatment for acute ischemic stroke, has a therapeutic window of only $2 \mathrm{~h}$ in mice (63). Considering that in clinic rtPA therapeutic window reaches $4.5 \mathrm{~h}$, we can extrapolate that in human, PACAP could still block development of the infarct area when injected $12 \mathrm{~h}$ after the ischemic event.

In mice, $15 \mathrm{~h}$ after reperfusion the infarct area is largely consolidated (64), so it is not surprising that PACAP has no more ability to reduce the lesion volume. Nevertheless, the gene expression data suggest that a delayed administration of PACAP after stroke could still shift the inflammatory response and stimulate synaptogenesis. These data correlate with the observation that injection of PACAP-producing stem cells, 3 days after permanent focal ischemia, do not reduce the ischemic lesion volume but shift the inflammatory response from a M1 to M2 phenotype and promote functional recovery (31).

\section{PACAP Dose Response Efficiency}

In accordance with the tMCAO protocol observations, a single IN administration of a very low dose of PACAP in a pMCAO also decreased infarct volume and enhanced sensorimotor performances, in accordance with what was previously reported through other routes of administration $[(65,66)$ and others referenced higher $]$. The fact that low doses of PACAP are sufficient to protect the brain from stroke, together with publications showing that PACAP-deficient mice exhibit increased lesions and enhanced neurological deficits (39, 67-69) suggests that any molecule, such as linagliptin, susceptible to increase endogenous PACAP levels could be of interest for the treatment of stroke.

\section{PACAP Delayed IN Daily Administration Efficiency}

Administration of PACAP started $6 \mathrm{~h}$ after pMCAO and repeated daily for 6 days led to a significant improvement in neurological function recovery and a reduction of the infarct volume. Surprisingly, when PACAP was administered $6 \mathrm{~h}$ after ischemia, the most important infarct volume reduction was observed in mice treated with the lowest concentration of PACAP ( $1 \mathrm{ng} / \mu \mathrm{l} /$ day). These results suggest that a daily reiteration of PACAP administration could at high doses induce desensitization of $\mathrm{PAC1}$ receptors through sequestration away from the membrane (70). Nevertheless, the PACAP treatment remained efficient and this result highlights the potential of low doses of PACAP, which will certainly decrease the risk of side effects.

\section{Gene Expression}

Ischemia is known to cause an early wave of glutamatergic excitotoxicity on depolarizing or dying neurons, resulting in breakdown of the homeostatic and water balances. Interestingly, several genes such as GAD1, GJB6, GJD2, and AQP4 known to be induced or repressed by those early events of stroke (71-74) are regulated in an opposite manner by PACAP which contributes to explain how PACAP protects the brain after stroke. For instance, PACAP by inhibiting AQP4, reduces brain oedema, and promotes cell survival after MCAO $(75,76)$. Likewise, PACAP injections $10 \mathrm{~min}$ or $1 \mathrm{~h}$ after reperfusion probably inhibit the deleterious action of glutamate by down-regulating GJB6 and up-regulating GJD2 (77). The observed repression of Tpa mRNA expression should also reduce stroke induced NMDA receptor-mediated signaling (78). Conversely, the fact that GAD1 expression is increased when PACAP is injected 1,6 , and $15 \mathrm{~h}$ after reperfusion suggests that $\mathrm{PACAP}$ also contributes to restore altered GABA levels after stroke (79), which must in turn reduce neuronal hyperexcitability.

Homeostatic disruption and the massive entry of ions inside the cell provoke a reactive oxygen/nitrogen species overproduction such as nNOS and iNOS $(80,81)$ causing severe intracellular damages to macromolecules and mitochondrial impairment, leading to apoptosis. It is thus interesting to note that PACAP represses the ischemic induction of NOS1 (a gene encoding nNOS) 
mRNA expression, which attenuates free radical production and in turn reduces oxidative stress. This may explain that $48 \mathrm{~h}$ after reperfusion, the expression of genes from the antioxidant system such as CAT, GPX1 and HMOX1 is reduced in PACAP treated animals. In addition, PACAP induction of GADD45A and GADD153/DDIT3 mRNA expression contributes to repair oxydative stress induced DNA damage (82-84), which reduces the number of cells entering apoptosis. The ability of PACAP to repress the expression of pro-apoptotic genes such as Caspase 9, PIK3R1, ATF3, FAS, or BCL10 and to promote the expression of anti-apoptotic genes such as Dusp6 provides further information on how PACAP prevents neuronal cell death. Of course, other molecular players are also involved in this neuroprotection mechanism. For example the blockage by PACAP of stroke induced c-Jun mRNA expression, supports the idea that it blocks apoptosis through an inhibition of the expression of proteins such as bax and a concomitant stimulation of BCL2 or BCL-XL as already shown in other experimental models $(29,85,86)$. Besides its neuroprotective effect, PACAP also reduces reactive astrogliosis as shown by its ability to inhibit stroke induced GFAP and VIM expression. Such effect of PACAP on GFAP and VIM expression decreases post-stroke astrocytic hypertrophy and contributes to brain protection (87-89).

Within minutes to hours after ischemia, an inflammatory response is initiated (41-90) whose intensity is strongly correlated with stroke severity (91). As already shown PACAP can skew the inflammatory response from a deleterious phenotype to a protective one $(28,31,67)$. The present results obtained with TLR4, IL6, or IRF1 confirm that PACAP can inhibit most proinflammatory mediators both when given rapidly or in a delayed manner after ischemia.

The ability of PACAP to stimulate the expression of genes such as BDNF, SLC16A7, NEUROD1, VEGFA, HOMER 1, or DBI/ACBP when administered either just after the occlusion or at later time points, highlights the ability of PACAP to not only block stroke induced apoptosis but also to promote subsequent synaptic plasticity and brain regeneration.

Taken together, the present gene expression results highlight the many protective pathways activated by PACAP after stroke both when administered within minutes after the reperfusion but still when provided $15 \mathrm{~h}$ after the stroke onset. One of the strengths of PACAP is probably its ability to reduce both neuronal cell death in the acute phase of stroke, to sustainably skew the inflammatory response toward a protective phenotype and to promote during the chronic phase of stroke the release of neurotrophic factors responsible for subsequent neuronal plasticity.

\section{CONCLUSION AND FUTURE PERSPECTIVES}

Neuronal cell death triggered by MCAO is initiated by several cellular events including excitotoxicity, free radical damages and inflammation which often activate apoptosis. Current research is focusing on candidate-drugs that may slow or prevent brain ischemic injury. There have been many unsuccessful therapeutic trials in stroke due to a single angle of attack. PACAP by modulating simultaneously different deleterious pathways activated by stroke could be a promising therapeutic molecule for the treatment of brain ischemia. However, the rapid degradation of the peptide and its numerous effects on the body require a method of delivery which targets specifically the brain. In this perspective, the present results showing the high efficiency of an IN PACAP administration are very promising. Future development should focus on the use of PACAP analogs and vectorization methods to increase the half-life of the peptide and its selectivity for PAC1 and VPAC1 receptors to further enhance its neuroprotective action while reducing possible side effects. It will also be interesting to study a potential combination therapy with PACAP and traditional stroke reperfusion methods (rtPA or endovascular thrombectomy) in order to see if PACAP can act as a freezing molecule of the penumbra to enhance the therapeutic window of the already approved reperfusion methods (6).

\section{DATA AVAILABILITY STATEMENT}

The raw data supporting the conclusions of this article will be made available by the authors, without undue reservation.

\section{ETHICS STATEMENT}

The animal study was reviewed and approved by the Regional committee of ethics for animal experimentation (CENOMEXA; approval number \#7619-2016101417048165) and conducted in an accredited animal facility (C7645104), according to the recommendations of the European Union under the supervision of authorized investigators.

\section{AUTHOR CONTRIBUTIONS}

AC and JM performed the experiments. BL and JL synthesized PACAP. Supervision and conceptualization were performed by DV. AC and DV wrote the manuscript. AC, JM, BL, JL, and DV revised the manuscripts. Final editing was performed by AC and DV. All authors contributed to the article and approved the submitted version.

\section{FUNDING}

AC was awarded a postdoctoral fellowship in neuroscience provided by Battuta Erasmus Mundus with the support of the European Commission and the cooperation of Badji Mokhtar University-Annaba, Algeria. This work was supported by INSERM (U1239), Rouen University, Normandy Region and the European Union. Europe gets involved in Normandy with European Regional Development Fund (ERDF). 


\section{REFERENCES}

1. Hankey GJ, Warlow CP. Treatment and secondary prevention of stroke: evidence, costs, and effects on individuals and populations. Lancet (1999) 354:1457-63. doi: 10.1016/S0140-6736(99)04407-4

2. Amarenco P, Bogousslavsky J, Caplan LR, Donnan GA, Hennerici MG. Classification of stroke subtypes. Cerebrovasc Dis (Basel Switzerland) (2009) 27(5):493-501. doi: 10.1159/000210432

3. Johnson W, Onuma O, Owolabi M, Sachdev S. Stroke: a global response is needed. Bull World Health Organ (2016) 94:634-634A. doi: 10.2471/ BLT.16.181636

4. Fekadu G, Wakassa H, Tekle F. Stroke event factors among adult patients admitted to stroke unit of Jimma university medical center: Prospective Observational Study. Stroke Res Treat (2019) 4650104. doi: 10.1155/2019/ 4650104

5. Truelsen T, Begg S, Mathers CD, Satoh T. The global burden of cerebrovascular disease in the year 2000. GBD 2000 working paper. Geneva: World Health Organisation (2000). Available at: https://www.who.int/ healthinfo/statistics/bod_cerebrovasculardiseasestroke.pdf?ua.

6. Baron JC. Protecting the ischaemic penumbra as an adjunct to thrombectomy for acute stroke. Nat Rev Neurol (2018) 14(6):325-37. doi: 10.1038/s41582018-0002-2

7. Fukuta T, Asai T, Yanagida Y, Namba M, Koide H, Shimizu K, et al. Combination therapy with liposomal neuroprotectants and tissue plasminogen activator for treatment of ischemic stroke. FASEB J (2017) 31 (5):1879-90. doi: 10.1096/fj.201601209r

8. Campbell BCV, Donnan GA, Mitchell PJ, Davis SM. Endovascular thrombectomy for stroke: current best practice and future goals. Stroke Vasc Neurol (2016) 1(1):16-22. doi: 10.1136/svn-2015-000004

9. Lansberg MG, Bluhmki E, Thijs VN. Efficacy and safety of tissue plasminogen activator 3 to 4.5 hours after acute ischemic stroke: a metaanalysis. Stroke (2009) 40:2438-41. doi: 10.1161/STROKEAHA.109.552547

10. Fluri F, Schuhmann MK, Kleinschnitz C. Animal models of ischemic stroke and their application in clinical research. Drug Des Dev Ther (2015) 9:344554. doi: 10.2147/DDDT.S56071

11. Vaudry D, Gonzalez BJ, Basille M, Yon L, Fournier A, Vaudry H. Pituitary adenylate cyclase-activating polypeptide and its receptors: from structure to functions. Pharmacol Rev (2000) 52(2):269-324.

12. Harmar AJ, Fahrenkrug J, Gozes I, Laburthe M, May V, Pisegna JR, et al. Pharmacology and functions of receptors for vasoactive intestinal peptide and pituitary adenylate cyclase-activating polypeptide: IUPHAR review $1 . \mathrm{Br} J$ Pharmacol (2012) 166(1):4-17. doi: 10.1111/j.1476-5381.2012.01871.x

13. Vaudry D, Falluel-Morel A, Bourgault S, Basille M, Burel D, Wurtz O, et al. Pituitary adenylate cyclase-activating polypeptide and its receptors: 20 years after the discovery. Pharmacol Rev (2009) 61(3):283-357. doi: 10.1124/ pr.109.001370

14. Jolivel V, Basille M, Aubert N, de Jouffrey S, Ancian P, Le Bigot JF, et al. Distribution and functional characterization of pituitary adenylate cyclaseactivating polypeptide receptors in the brain of non-human primates. Neuroscience (2009) 160(2):434-51. doi: 10.1016/j.neuroscience.2009.02.028

15. Shen S, Gehlert DR, Collier DA. PACAP and PAC1 receptor in brain development and behavior. Neuropeptides (2013) 47(6):421-30. doi: 10.1016/j.npep.2013.10.005

16. Reglodi D, Atlasz T, Jungling A, Szabo E, Kovari P, Manavalan S, et al. Alternative routes of administration of the neuroprotective pituitary adenylate cyclase activating polypeptide. Curr Pharm Des (2018) 24(33):3892-904. doi: 10.2174/1381612824666181112110934

17. Waschek JA. Multiple actions of pituitary adenylyl cyclase activating peptide in nervous system development and regeneration. Dev Neurosci (2002) 24 (1):14-23. doi: 10.1159/000064942

18. Dejda A, Jolivel V, Bourgault S, Seaborn T, Fournier A, Vaudry H, et al. Inhibitory effect of PACAP on caspase activity in neuronal apoptosis: a better understanding towards therapeutic applications in neurodegenerative diseases. J Mol Neurosci (2008) 36(1-3):26-37. doi: 10.1007/s12031-008-9087-1

19. Lee EH, Seo SR. Neuroprotective roles of pituitary adenylate cyclase-activating polypeptide in neurodegenerative diseases. BMB Rep (2014) 47(7):369-75. doi: 10.5483/BMBRep.2014.47.7.086
20. De Souza O, Resende F, Fabiola Mara R, Patrícia M, Almeida L. Implications of VIP and PACAP in parkinson's disease: What do we know so far? Curr Med Chem (2020) 27:1. doi: 10.2174/0929867327666200320162436

21. Lamine-Ajili A, Fahmy AF, Létourneau M, Chatenet D, Labonté P, Vaudry D, et al. Effect of the pituitary adenylate cyclase-activating polypeptide on the autophagic activation observed in in vitro and in vivo models of Parkinson's disease. Biochim Biophys Acta (2016) 1862:688-95. doi: 10.3791/237610.1016/ j.bbadis.2016.01.005

22. Maasz G, Zrinyi Z, Reglodi D, Petrovics D, Rivnyak A, Kiss T, et al. Pituitary adenylate cyclase-activating polypeptide (PACAP) has a neuroprotective function in dopamine-based neurodegeneration in rat and snail parkinsonian models. Dis Models Mech (2017) 10(2):127-39. doi: 10.1242/ dmm. 027185

23. Rat D, Schmitt U, Tippmann F, Dewachter I, Theunis C, Wieczerzak E, et al. Neuropeptide pituitary adenylate cyclase-activating polypeptide (PACAP) slows down Alzheimer's disease-like pathology in amyloid precursor protein-transgenic mice. FASEB J (2011) 25(9):3208-18. doi: 10.1096/fj.10180133

24. Ribari S. Peptides as potential therapeutics for alzheimer's disease. Molecules (2018) 23:283. doi: 10.3390/molecules 23020283

25. Shi L, Baird AL, Westwood S, Hye A, Dobson R, Thambisetty M, et al. A decade of blood biomarkers for alzheimer's disease research: an evolving field, improving study designs, and the challenge of replication. J Alzheimers Dis (2018) 62(3):1181-98. doi: 10.3233/JAD-170531

26. Shioda S, Nakamachi T. PACAP as a neuroprotective factor in ischemic neuronal injuries. Peptides (2015) 72:202-7. doi: 10.1016/j.peptides.2015.08.006

27. Cabezas-Llobet N, Vidal-Sancho L, Masana M, Fournier A, Alberch J, Vaudry $\mathrm{D}$, et al. Pituitary adenylate cyclase-activating polypeptide (PACAP) enhances hippocampal synaptic plasticity and improves memory performance in huntington's disease. Mol Neurobiol (2018) 55(11):8263-77. doi: 10.1007/ s12035-018-0972-5

28. Dejda A, Seaborn T, Bourgault S, Touzani O, Fournier A, Vaudry H, et al. PACAP and a novel stable analog protect rat brain from ischemia: Insight into the mechanisms of action. Peptides (2011) 32:1207-16. doi: 10.1016/ j.peptides.2011.04.003

29. Seaborn T, Masmoudi-Kouli O, Fournier A, Vaudry H, Vaudry D. Protective effects of pituitary adenylate cyclase-activating polypeptide (PACAP) against apoptosis. Curr Pharm Des (2011) 17(3):204-14. doi: 10.2174/ 138161211795049679

30. Jayakar S, Pugh P, Dale Z, Starr E, Cole S, Margiotta J. PACAP induces plasticity at autonomic synapses by nAChR-dependent NOS1 activation and AKAP-mediated PKA targeting. Mol Cell Neurosci (2014) 63:1-12. doi: 10.1016/j.mcn.2014.08.007

31. Brifault C, Gras M, Liot D, May V, Vaudry D, Wurtz O. Delayed pituitary adenylate cyclase-activating polypeptide delivery after brain stroke improves functional recovery by inducing $\mathrm{m} 2 \mathrm{microglia} / \mathrm{macrophage}$ polarization. Stroke (2015) 46:520-8. doi: 10.1161/STROKEAHA.114.006864

32. Matsumoto M, Nakamachi T, Watanabe J, Sugiyama K, Ohtaki H, Murai N, et al. Pituitary adenylate cyclase-activating polypeptide (PACAP) is involved in adult mouse hippocampal neurogenesis after stroke. J Mol Neurosci (2016) 59:270-9. doi: 10.1007/s12031-016-0731-x

33. Rivnyak A, Kiss P, Tamas A, Balogh D, Reglodi D. Review on PACAPinduced transcriptomic and proteomic changes in neuronal development and repair. Int J Mol Sci (2018) 19(4):1020. doi: 10.3390/ijms19041020

34. Bourgault S, Vaudry D, Botia B, Couvineau A, Laburthe M, Vaudry H, et al. Novel stable PACAP analogs with potent activity towards the PAC1 receptor. Peptides (2008) 29(6):919-32. doi: 10.1016/j.peptides.2008.01.022

35. Koizumi J, Yoshida Y, Nakazawa T, Ooneda G. Experimental studies of ischemic brain edema 1. A new experimental model of cerebral embolism in rats in which recirculation can be introduced in the ischemic area. Jpn J Stroke (1986) 8:1-8. doi: 10.3995/jstroke.8.1

36. Luong TN, Carlisle HJ, Southwell A, Patterson PH. Assessment of motor balance and coordination in mice using the balance beam. J Vis Exp (2011) 49:2376. doi: 10.3791/2376

37. Bouet V, Boulouard M, Toutain J, Divoux D, Bernaudin M, Schumann-Bard $\mathrm{P}$, et al. The adhesive removal test: a sensitive method to assess sensorimotor deficits in mice. Nat Protoc (2009) 4:1560-4. doi: 10.1038/nprot.2009.125 
38. Longa EZ, Weinstein PR, Carlson S, Cummins R. Reversible middle cerebral artery occlusion without craniectomy in rats. Stroke (1989) 20(1):84-91. doi: 10.3791/237610.1161/01.str.20.1.84

39. Chen Y, Samal B, Hamelink CR, Xiang CC, Chen Y, Chen M, et al. Neuroprotection by endogenous and exogenous PACAP following stroke. Regul Pept (2006) 137(1-2):4-19. doi: 10.1016/j.regpep.2006.06.016

40. Xing C, Arai K, Lo EH, Hommel M. Pathophysiologic cascades in ischemic stroke. Int J Stroke (2012) 7(5):378-85. doi: 10.1111/j.1747-4949.2012.00839.x

41. Jayaraj RL, Azimullah S, Beiram R, Jalal FY, Rosenberg GA. Neuroinflammation: friend and foe for ischemic stroke. J Neuroinflammation (2019) 16(1):142. doi: 10.1186/s12974-019-1516-2

42. Caballero-Garrido E, Pena-Philippides JC, Lordkipanidze T, Bragin D, Yang $\mathrm{Y}$, Erhardt EB, et al. In vivo inhibition of miR-155 promotes recovery after experimental mouse stroke. J Neurosci (2015) 35(36):12446-64. doi: 10.1523/ JNEUROSCI.1641-15.2015

43. Tachibana T, Saito ES, Takahashi H, Saito S, Tomonaga S, Boswell T, et al. Anorexigenic effects of pituitary adenylate cyclase-activating polypeptide and vasoactive intestinal peptide in the chick brain are mediated by corticotrophin-releasing factor. Regul Pept (2004) 120:99-105. doi: 10.1016/ j.regpep.2004.02.016

44. Matsuda K, Maruyama K, Nakamachi T, Miura T, Uchiyama M, Shioda S. Inhibitory effects of pituitary adenylate cyclase-activating polypeptide (PACAP) and vasoactive intestinal peptide (VIP) on food intake in the goldfish, Carassius auratus. Peptides (2005) 26:1611-6. doi: 10.1016/ j.peptides.2005.02.022

45. Nakamachi T, Tanigawa A, Konno N, Shioda S, Matsuda K. Expression patterns of PACAP and PAC1R genes and anorexigenic action of PACAP1 and PACAP2 in zebrafish. Front Endocrinol (Lausanne) (2019) 10:227. doi: $10.3389 /$ fendo.2019.00227

46. Iemolo A, Ferragud A, Cottone P, Sabino V. Pituitary adenylate cyclaseactivating peptide in the central amygdala causes anorexia and body weight loss via the melanocortin and the trkb systems. Neuropsychopharmacology (2015) 40(8):1846-55. doi: 10.1038/npp.2015.34

47. Hurley MM, Maunze B, Block ME, Frenkel MM, Reilly MJ, Kim E, et al. Pituitary adenylate-cyclase activating polypeptide regulates hunger- and palatability-induced binge eating. Front Neurosci (2016) 10:383. doi: $10.3389 /$ fnins. 2016.00383

48. Tamás A, Reglõdi D, Szántó Z, Borsiczky B, Németh J, Lengvári I. Comparative neuroprotective effects of preischemic PACAP and VIP administration in permanent occlusion of the middle cerebral artery in rats. Neuro Endocrinol Lett (2002) 23(3):249-54.

49. Green BD, Irwin N, Flatt PR. Pituitary adenylate cyclase-activating peptide (PACAP): assessment of dipeptidyl peptidase IV degradation, insulinreleasing activity and antidiabetic potential. Peptides (2006) 27(6):1349-58. doi: 10.1016/j.peptides.2005.11.010

50. Marzagalli R, Scuderi S, Drago F, Waschek JA, Castorina A. Emerging role of pacap as a new potential therapeutic target in major diabetes complications. Int J Endocrinol (2015) 160928:1-11. doi: 10.1155/2015/160928

51. Lin CH, Chiu L, Lee HT, Chiang CW, Liu SP, Hsu YH, et al. PACAP38/PAC1 signaling induces bone marrow-derived cells homing to ischemic brain. Stem Cells (Dayton Ohio) (2015) 33(4):1153-72. doi: 10.1002/stem.1915

52. Nonaka N, Farr SA, Nakamachi T, Morley JE, Nakamura M, Shioda S, et al. Intranasal administration of PACAP: uptake by brain and regional brain targeting with cyclodextrins. Peptides (2012) 36(2):168-75. doi: 10.1016/ j.peptides.2012.05.021

53. Hawke Z, Ivanov TR, Bechtold DA, Dhillon H, Lowell BB, Luckman SM. PACAP neurons in the hypothalamic ventromedial nucleus are targets of central leptin signaling. J Neurosci (2009) 29(47):14828-35. doi: 10.1523/ JNEUROSCI.1526-09.2009

54. Kocho-Schellenberg M, Lezak KR, Harris OM, Roelke E, Gick N, Choi I, et al. PACAP in the BNST produces anorexia and weight loss in male and female rats. Neuropsychopharmacology (2014) 39(7):1614-23. doi: 10.1038/npp.2014.8

55. Vu JP, Goyal D, Luong L, Oh S, Sandhu R, Norris J, et al. PACAP intraperitoneal treatment suppresses appetite and food intake via PAC1 receptor in mice by inhibiting ghrelin and increasing GLP-1 and leptin. American journal of physiology. Gastrointest Liver Physiol (2015) 309(10): G816-25. doi: 10.1152/ajpgi.00190.2015
56. Bourgault S. Development of stable agonists of the PAC1 receptor: study of the structure-activity relationships of the pituitary adenylate cyclase activator polypeptide. Doctoral thesis in Cellular Biology. Medicinal chemistry and neuroscience. France: Normandie University Rouen (2009). p. P118-9.

57. Mounien L, Do Rego J-C, Bizet P, Boutelet I, Gourcerol G, Fournier A, et al. Pituitary adenylate cyclase-activating polypeptide inhibits food intake in mice through activation of the hypothalamic melanocortin system. Neuropsychopharmacology (2009) 34(2):424-35. doi: 10.1038/npp.2008.73

58. Leibowitz SF, Wortley KE. Hypothalamic control of energy balance: different peptides, different functions. Peptides (2004) 25(3):473-504. doi: 10.1016/ j.peptides.2004.02.006

59. Will MJ, Franzblau EB, Kelley AE. The amygdala is critical for opioidmediated binge eating of fat. Neuroreport (2004) 15(12):1857-60. doi: 10.1097/00001756-200408260-00004

60. Marx D, Williams G, Birkhoff M. Intranasal drug administration - an attractive delivery route for some drugs, in: Drug discovery and development- from molecules to medicine (2015). (Accessed September 30, 2019).

61. Li Q, Levine CF, Wang J. Therapeutic potential of intranasal drug delivery in preclinical studies of ischemic stroke and intracerebral hemorrhage. Nature Springer Switzerland: Springer Series in Translational Stroke Research (2019). p. 27-42. doi: 10.1007/978-3-030-16715-8_3

62. Meredith ME, Salameh TS, Banks WA. Intranasal delivery of proteins and peptides in the treatment of neurodegenerative diseases. AAPS J (2015) 17 (4):780-7. doi: 10.1208/s12248-015-9719-7

63. Macrez R, Ali C, Toutirais O, Le Mauff B, Defer G, Dirnagl U, et al. Stroke and the immune system: from pathophysiology to new therapeutic strategies. Lancet Neurol (2011) 10(5):471-80. doi: 10.1016/S1474-4422(11)70066-7

64. Hossmann KA. The two pathophysiologies of focal brain ischemia: implications for translational stroke research. J Cereb Blood Flow Metab (2012) 32:1310-6. doi: 10.1038/jcbfm.2011.186

65. Lazarovici P, Cohen G, Arien-Zakay H, Chen J, Zhang C, Chopp M, et al. Multimodal neuroprotection induced by PACAP38 in oxygen-glucose deprivation and middle cerebral artery occlusion stroke models. $J \mathrm{Mol}$ Neurosci (2012) 48(3):526-40. doi: 10.1007/s12031-012-9818-1

66. Miyamoto K, Tsumuraya T, Ohtaki H, Dohi K, Satoh K, Xu Z, et al. PACAP38 suppresses cortical damage in mice with traumatic brain injury by enhancing antioxidant activity. J Mol Neurosci (2014) 54:370-9. doi: 10.1007/s12031014-0309-4

67. Ohtaki H, Nakamachi T, Dohi K, Aizawa Y, Takaki A, Hodoyama K, et al. Pituitary adenylate cyclase-activating polypeptide (PACAP) decreases ischemic neuronal cell death in association with IL-6. Proc Natl Acad Sci U S A (2006) 103:7488-93. doi: 10.1073/pnas.0600375103

68. Reglodi D, Kiss P, Szabadfi K, Atlasz T, Gabriel R, Horvath G, et al. PACAP is an endogenous protective factor-insights from PACAP-deficient mice. J Mol Neurosci (2012) 48(3):482-92. doi: 10.1007/s12031-012-9762-0

69. Szabadfi K, Atlasz T, Kiss P, Danyadi B, Tamas A, Helyes Z, et al. Mice deficient in pituitary adenylate cyclase activating polypeptide (PACAP) are more susceptible to retinal ischemic injury in vivo. Neurotox Res (2012) 21 (1):41-8. doi: 10.1007/s12640-011-9254-y

70. Shintani N, Hashimoto H, Kunugi A, Koyama Y, Yamamoto K, Tomimoto S, et al. Desensitization, surface expression, and glycosylation of a functional, epitope-tagged type I PACAP (PAC(1)) receptor. Biochim Biophys Acta (2000) 1509(1-2):195-202. doi: 10.1016/s0005-2736(00)00295-9

71. Apostolides PF, Trussell LO. Regulation of interneuron excitability by gap junction coupling with principal cells. Nat Neurosci (2013) 16(12):1764-72. doi: $10.1038 / \mathrm{nn} .3569$

72. Dergunova LV, Filippenkov IB, Stavchansky VV, Denisova AE, Yuzhakov VV, Mozerov SA, et al. Genome-wide transcriptome analysis using RNA-Seq reveals a large number of differentially expressed genes in a transient MCAO rat model. BMC Genomics (2018) 19(1):655. doi: 10.1186/s12864-018-5039-5

73. Hubbard JA, Szu JII, Binder DK. The role of aquaporin-4 in synaptic plasticity, memory and disease. Brain Res Bull (2018) 136:118-29. doi: 10.1016/j.brainresbull.2017.02.011

74. You J, Feng L, Xin M, Ma D, Feng J. Cerebral Ischemic Postconditioning Plays a Neuroprotective Role through Regulation of Central and Peripheral Glutamate. BioMed Res Int (2018) 2018:6316059. doi: 10.1155/2018/6316059 
75. Manley GT, Fujimura M, Ma T, Noshita N, Filiz F, Bollen AW, et al. Aquaporin-4 deletion in mice reduces brain edema after acute water intoxication and ischemic stroke. Nat Med (2000) 6:159-63. doi: 10.1038/ 72256

76. Hirt L, Fukuda AM, Ambadipudi K, Rashid F, Binder D, Verkman A, et al. Improved long-term outcome after transient cerebral ischemia in aquaporin-4 knockout mice. J Cereb Blood Flow Metab (2017) 37(1):277-90. doi: 10.1177/ 0271678X15623290

77. Feustel PJ, Jin Y, Kimelberg HK. Volume-regulated anion channels are the predominant contributors to release of excitatory amino acids in the ischemic cortical penumbra. Stroke (2004) 35(5):1164-8. doi: 10.1161/01.STR. 0000124127.57946.a1

78. Nicole O, Docagne F, Ali C, Margaill I, Carmeliet P, MacKenzie ET, et al. The proteolytic activity of tissue-plasminogen activator enhances NMDA receptor-mediated signaling. Nat Med (2001) 7(1):59-64. doi: 10.1038/83358

79. Blicher JU, Near J, Næss-Schmidt E, Stagg CJ, Johansen-Berg H, Nielsen JF, et al. GABA levels are decreased after stroke and GABA changes during rehabilitation correlate with motor improvement. Neurorehabil Neural Repair (2015) 29(3):278-86. doi: 10.1177/1545968314543652

80. Chen ZQ, Mou RT, Feng DX, Wang Z, Chen G. The role of nitric oxide in stroke. Med Gas Res (2017) 7(3):194-203. doi: 10.4103/2045-9912.215750

81. Feno S, Butera G, Vecellio Reane D, Rizzuto R, Raffaello A. Crosstalk between Calcium and ROS in Pathophysiological Conditions. Oxid Med Cell Longevity (2019) 2019:9324018. doi: 10.1155/2019/9324018

82. Barreto G, Schäfer A, Marhold J, Stach D, Swaminathan SK, Handa V, et al. Gadd45a promotes epigenetic gene activation by repair-mediated DNA demethylation. Nature (2007) 445(7128):671-5. doi: 10.1038/nature05515

83. Lacaille H, Duterte-Boucher D, Liot D, Vaudry H, Naassila M, Vaudry D. Comparison of the deleterious effects of binge drinking-like alcohol exposure in adolescent and adult mice. J Neurochem (2015) 132(6):629-41. doi: $10.1111 /$ jnc. 13020

84. Yang W, Paschen W. Unfolded protein response in brain ischemia: A timely update. J Cereb Blood Flow Metab (2016) 36(12):2044-50. doi: 10.1177/ 0271678X16674488

85. Aubert N, Vaudry D, Falluel-Morel A, Desfeux A, Fisch C, Ancian P, et al. PACAP prevents toxicity induced by cisplatin in rat and primate neurons but not in proliferating ovary cells: involvement of the mitochondrial apoptotic pathway. Neurobiol Dis (2008) 32(1):66-80. doi: 10.1016/j.nbd.2008.06.014

86. Doyle KP, Simon RP, Stenzel-Poore MP. Mechanisms of ischemic brain damage. Neuropharmacology (2008) 55(3):310-8. doi: 10.1016/ j.neuropharm.2008.01.005

87. Wilhelmsson U, Li L, Pekna M, Berthold CH, Blom S, Eliasson C, et al. Absence of glial fibrillary acidic protein and vimentin prevents hypertrophy of astrocytic processes and improves post-traumatic regeneration. J Neurosci (2004) 24(21):5016-21. doi: 10.1523/JNEUROSCI.0820-04.2004

88. Wilhelmsson U, Faiz M, de Pablo Y, Sjöqvist M, Andersson D, Widestrand A, et al. Astrocytes negatively regulate neurogenesis through the Jagged1mediated Notch pathway. Stem Cells (Dayton Ohio) (2012) 30(10):2320-9. doi: 10.1002/stem.1196

89. Fasipe TA, Hong SH, Da Q, Valladolid C, Lahey MT, Richards LM, et al. Extracellular vimentin/VWF (von willebrand factor) interaction contributes to vwf string formation and stroke pathology. Stroke (2018) 49(10):2536-40. doi: 10.1161/STROKEAHA.118.022888

90. Moskowitz MA, Lo EH, Iadecola C. The science of stroke: mechanisms in search of treatments. Neuron (2010) 67(2):181-98. doi: 10.1016/ j.neuron.2010.07.002

91. Basic Kes V, Simundic AM, Nikolac N, Topic E, Demarin V. Proinflammatory and anti-inflammatory cytokines in acute ischemic stroke and their relation to early neurological deficit and stroke outcome. Clin Biochem (2008) 41(16-17):1330-4. doi: 10.1016/j.clinbiochem.2008.08.080

Conflict of Interest: The authors declare that the research was conducted in the absence of any commercial or financial relationships that could be construed as a potential conflict of interest.

Copyright (C) 2021 Cherait, Maucotel, Lefranc, Leprince and Vaudry. This is an openaccess article distributed under the terms of the Creative Commons Attribution License (CC BY). The use, distribution or reproduction in other forums is permitted, provided the original author(s) and the copyright owner(s) are credited and that the original publication in this journal is cited, in accordance with accepted academic practice. No use, distribution or reproduction is permitted which does not comply with these terms. 